\title{
Stereoselective synthesis and stereochemistry of seven isomeric spiroacetal structures based on the C17-C28 fragment (CD rings) of spongistatin 1
}

\author{
Mark F. Jacobs ${ }^{\mathrm{a}}$, Matthew P. Glenn ${ }^{\mathrm{a}}$, Matthew J. McGrath ${ }^{\mathrm{a}}$, Hesheng Zhang, ${ }^{\mathrm{a}}$ Ian \\ Brereton $^{\mathrm{b}}$, and William Kitching ${ }^{\mathrm{a}^{*}}$ \\ ${ }^{a}$ Department of Chemistry, The University of Queensland, Brisbane, Qld, 4072 Australia \\ ${ }^{b}$ Centre for Magnetic Resonance, The University of Queensland, Brisbane, Qld. 4072, Australia \\ E-mail: kitching@chemistry.uq.edu.au
}

\section{Dedicated to Prof. Don Cameron on the occasion of his retirement \\ (received 28 Jun 01; accepted 14 Oct 01; published on the web 22 Oct 01)}

\begin{abstract}
Brown allylation methodology has been employed to provide seven of the eight possible isomers of the (ZE)(EZ) spiroacetal system representing the CD ring fragment (C17-C28) of spongistatin 1. The stereochemistry of the isomers follows from high-field NMR examinations which furnish insights into the trends in the NMR data for these ketal structures.
\end{abstract}

Keywords: Stereoselective synthesis, spiroacetal, spongistatin, high-field nuclear magnetic resonance

\section{Introduction}

In 1993-1994, the isolation of several series of marine-based macrolides was reported. These spongipyrans comprised the spongistatins, cinachyrolides and altohyrtins which exhibit extremely potent anti-tumour activity. ${ }^{1-7}$ There has been enormous interest in the pharmacology, structures and stereochemistry of these systems which are available in only meagre amounts from their sponge sources. A number of syntheses of key sub- structures, ${ }^{8}$ and several total syntheses $^{9,10,11}$ have been reported. Synthesis of altohyrtin C (identical with spongistatin 2) and altohyrtin A (spongistatin 1) have defined the relative and absolute stereochemistry of the natural compounds ${ }^{5}$ which is shown below in Figure 1, and considered to represent this spongipyran group. The members of these families of metabolites differ with respect to the substituents at C5, C15 and C50.

Sub-structure syntheses have focussed on the retrosynthetically attractive $A B$ and $C D$ spiroacetal assemblies and the EF tetrahydropyran moiety. These partial syntheses are 
noteworthy as it may be that the most efficient total synthesis will select from the list of syntheses of the key, readily linked, sub-structures. Much of this synthetic endeavour has been summarised. $^{6,8}$

In this report, we describe synthetic approaches to the CD spiroacetal system (C17-C28) ${ }^{12}$ and at the time this work commenced (1995), there was stereochemical uncertainty regarding the relationship between the spongistatins, altohyrtins and cinachyrolide groups. ${ }^{5}$ Our approach, at the outset, was to control the stereochemistry at C19 and C27 by asymmetric induction methods, and separate and examine the suite of spiroacetals that would result from lack of control at C21, C25 and the created spirocentre, C23. The structures of the resulting spiroacetals would provide insights into the thermodynamics ${ }^{13}$ of these systems, whereas the fully assigned NMR spectra would clarify chemical shift trends and nOe's that would be valuable when additional stereocontrol was incorporated.
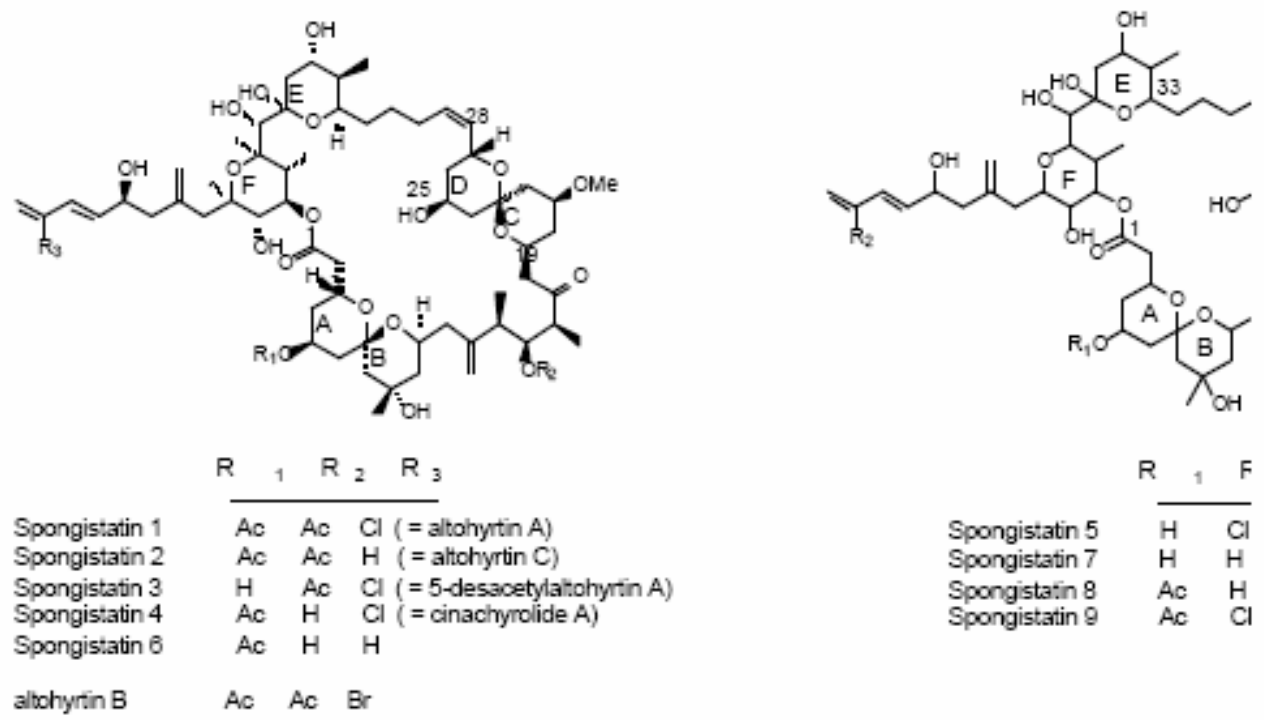

Figure 1. Structures of the spongistatins, altohyrtins, cinachyrolide A.

The CD system is stabilised by a single anomeric effect (in contrast with the AB spiroacetal system) and hence there is a question whether the required $Z E$ or $E Z$ system would be favoured, and which isomer(s) within each of these systems. This feature has been considered and regulated in a number of syntheses, ${ }^{9,12}$ and equilibration-separation- equilibration cycles have been utilised. Given the free-energy similarities, choice of protection groups on the various oxyfunctions could influence these equilibria. (In the assignment of the $Z E, E Z$ descriptors, ${ }^{14}$ the $\mathrm{C}$ ring has priority over the $\mathrm{D}$ ring, and the first descriptor always refers to the $\mathrm{C}$ ring, and the second to the $\mathrm{D}$ ring. In addition, if the ring substituents attached to the carbon atoms linked to the tetrahydropyranyl (ring) oxygen, are cis, then $Z$ is used, and if trans, $E$ is applied.) $C D$ spiroacetal. 


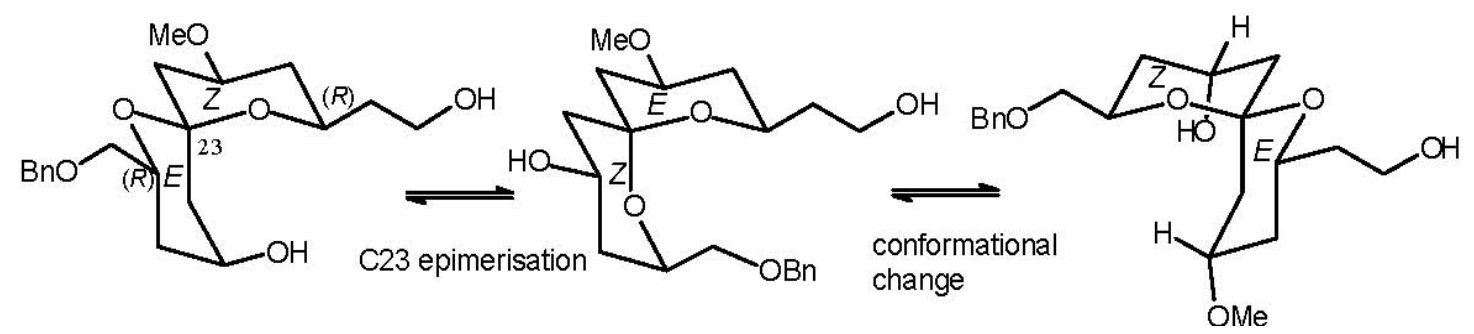

Figure 2. Illustrative spirocentre epimerisation and conformational reversal: $Z E \equiv E Z$ interconversion in the CD system.

\section{Results and Discussion}

Excision of the CD spiroacetal unit from spongistatin leads to spiroacetal $\mathbf{1}$ which may be modified to 1a and unravelled to ketohexol 2. The latter was planned to result from dithiane coupling of two $\exists$ oxy epoxides $\mathbf{3}$ and $\mathbf{4}$, as shown below.
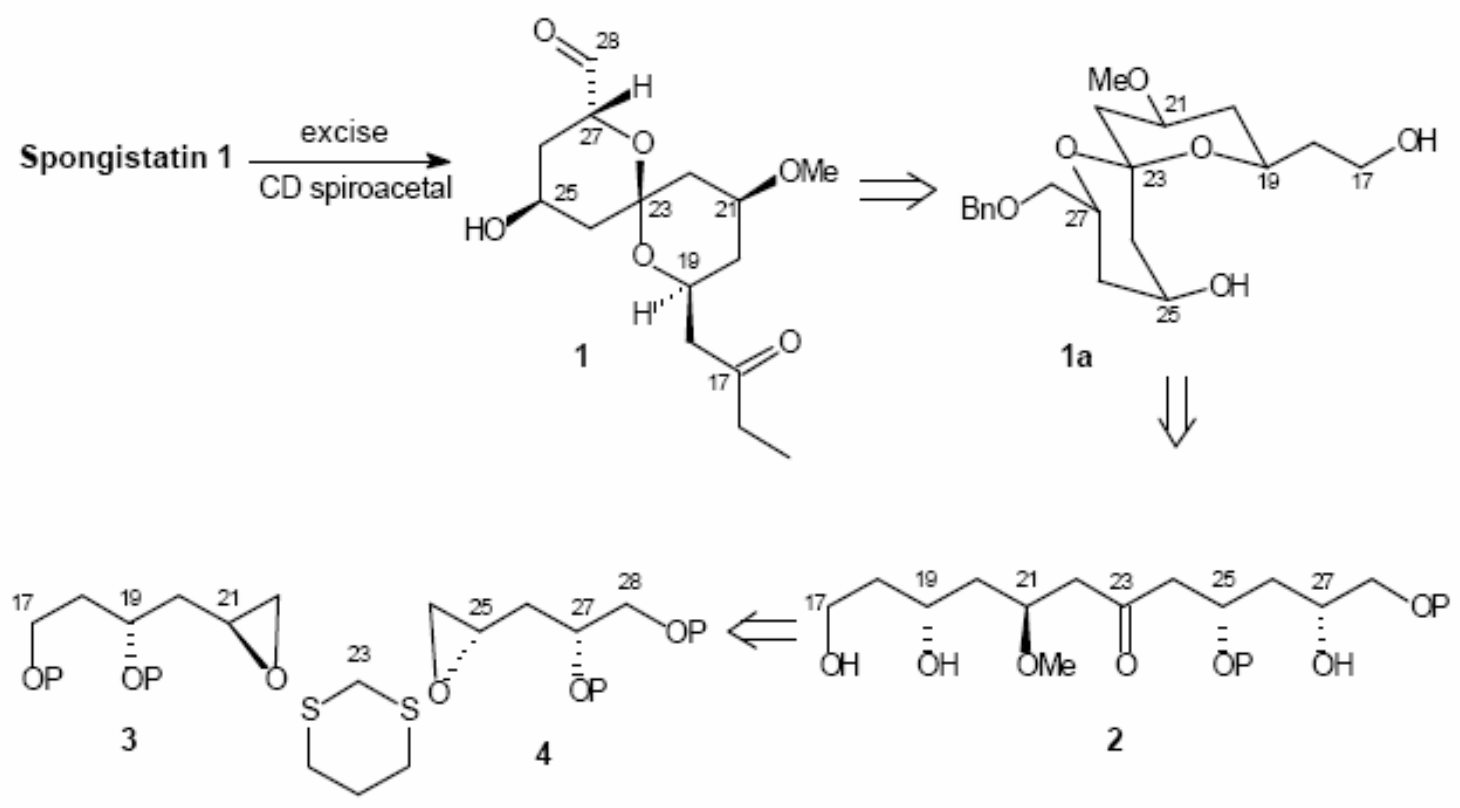

Figure 3. Retrosynthetic analysis of the CD spiroacetal.

Arrangement 2 incorporates four stereogenic centres which increases to five on spiroacetalisation (C23). Our approach to open-chain precursor 2 incorporated control at C27 and C19, so that in principle, the final spiroacetal could be a mixture of eight diastereomers, with centers at C25, C23 and C21 uncontrolled. Construction of the chiral epoxides $\mathbf{3}$ and $\mathbf{4}$ was achieved with moderate to high asymmetric induction at (C19, C21) and (C25, C27) as outlined below. The route to epoxide $\mathbf{4}$ utilised the bis-benzyl ether $\mathbf{5}$ of 2-buten-1,4-diol and ozonolysis provided the benzyloxy aldehyde $\mathbf{6}^{15}$ Asymmetric allylation of this aldehyde, employing 
Brown's B-allybis(isocaranyl)borane (4- Icr2Ball, 7), ${ }^{16}$ provided 8 with an ee exceeding 95\%, based on NMR analysis of its Moshers ester. This was consistent with Brown's original reports and agrees with the results of Paterson. ${ }^{12(b)}$

Epoxidation ( $m$-CPBA) of $\mathbf{8}$ provided the desired epoxide $\mathbf{9}$ as a mixture of diastereomers, which were protected as the TES ethers, 10. These were prone to decomposition and were stored at low temperature $\left(-78^{\circ} \mathrm{C}\right)$. (Scheme 1$)$
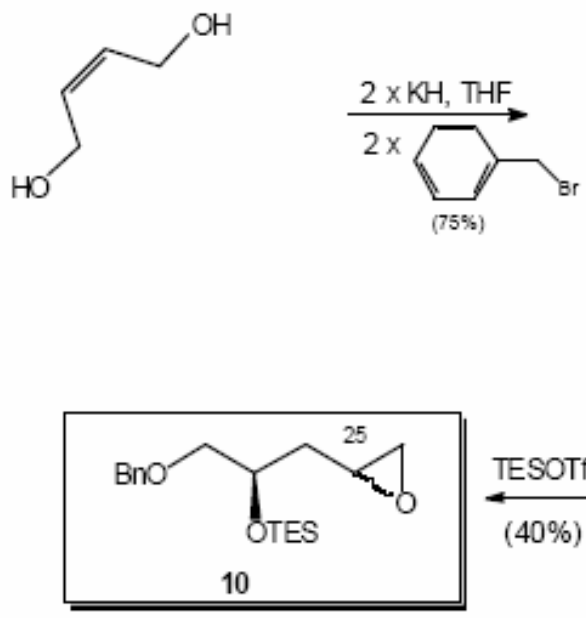
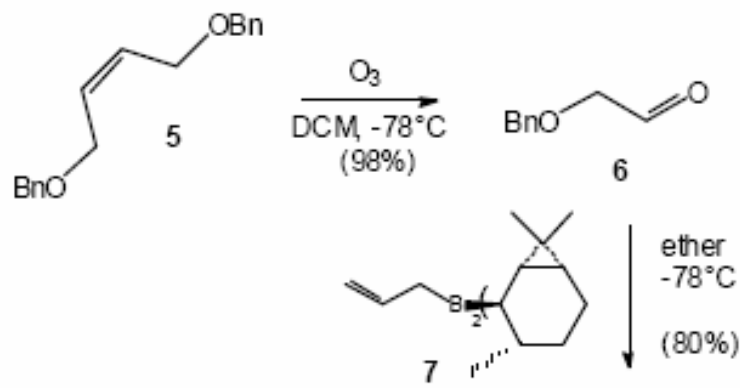

$$
\frac{\text { TESOTf }}{(40 \%)}
$$
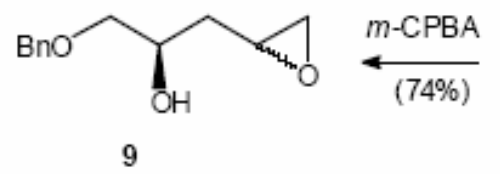

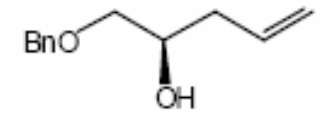

8

Scheme 1. Synthesis of the chiral epoxide 10.

Epoxide 20 (cf.3) was synthesised, as for $\mathbf{1 0}$ but starting from the $p$ - methoxybenzyl derivative of but-3-enol. Ozonolysis (careful TLC to monitor any over oxidation) provided aldehyde 13 which with Brown's carenyl-based allylating reagent 14 provided the desired allyl alcohol 15 (>95\% ee by Mosher ester analysis) but in moderate yield. Elaboration to the epoxides 17 and 20 proceeded as shown in Scheme 2, with 17 being a mixture of epimers at C21.

Thus, epoxidation with $m$-CPBA of the hydroxy alkene 15 provided hydroxy epoxide 16, and oxidative cyclisation of the $p$-methoxybenzyl group with DDQ in the presence of $4 \Delta$ sieves, afforded the required epoxide 17 in $42 \%$ yield. This epoxide was used in initial studies of the dithiane alkylations described below. Alternatively, DDQ-mediated cyclisation of the $p-$ methoxybenzyl group of $\mathbf{1 5}$ provided the alkene $\mathbf{1 8}$ which served as a substrate for the Sharpless dihydroxylation protocol to deliver diol 19. Transformation of the diol to the chiral epoxide 20 proceeded via the corresponding tosylate. 

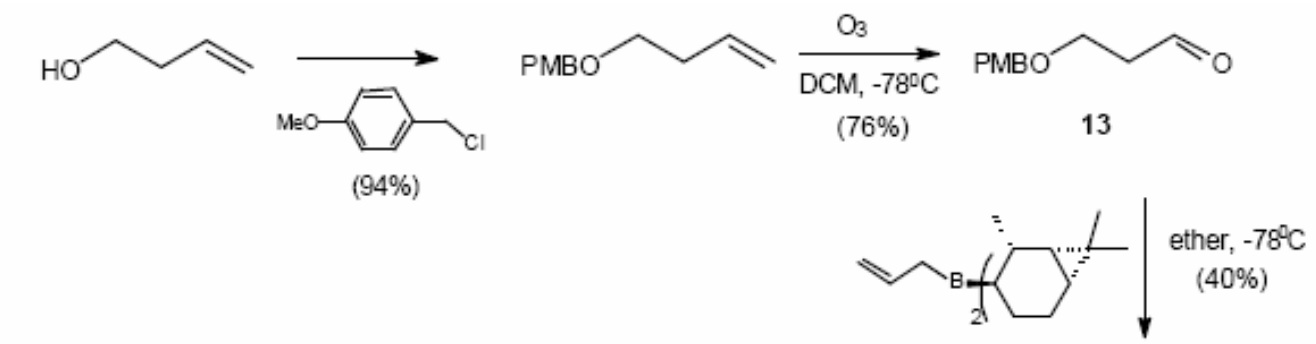

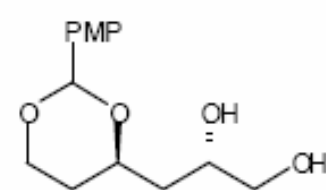

19
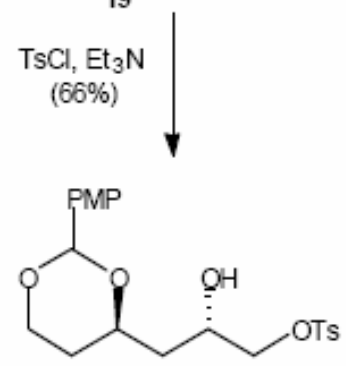

$\mathrm{K}_{2} \mathrm{CO}_{3}$,

$\mathrm{MeOH}$

$(80 \%)$

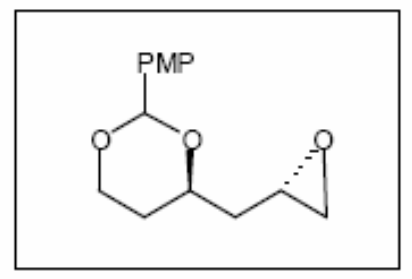

20

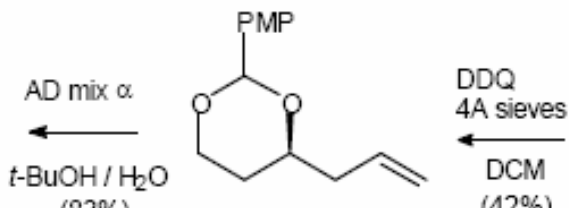

18

(42\%)

14
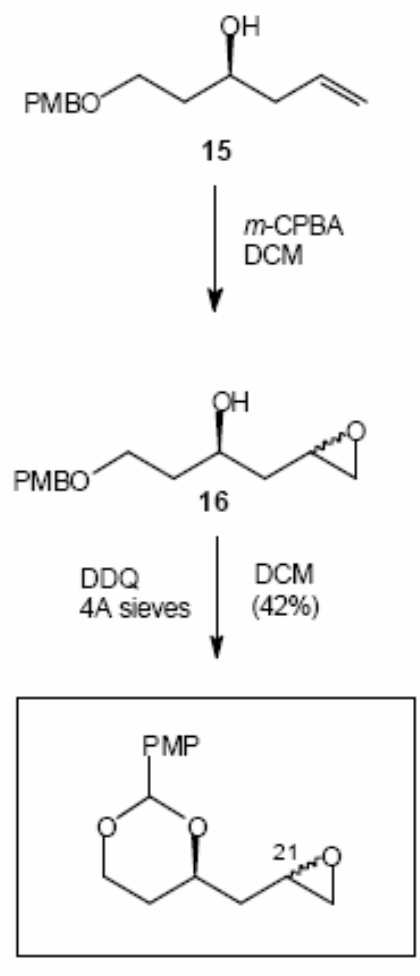

17

Scheme 2. Synthesis of the Chiral Epoxides 17 and 20.

The coupling of 1,3-dithiane and the epoxide 17 at low temperature $\left(-40{ }^{\circ} \mathrm{C}\right)$ (Scheme 3) proceeded efficiently (73\%) to provide the monalkylated adduct $\mathbf{2 1}$ which was protected as the methyl ether. Suitable conditions for the opening of epoxide $\mathbf{1 0}$ by deprotonated 22 proved difficult to optimise. In our hands, tbutyl lithium in THF containing 10\% HMPA (freshly distilled) provided the best outcome and $\mathbf{2 3}$ was obtained as a diastereomeric mixture. Treatment of this with Stork's reagent, (bistrifluoroacetoxyiodobenzene) unmasked the carbonyl moiety, removed the $p$-methoxybenzyl acetal and the triethylsilyl group and effected cyclisation to a mixture of spiroacetals 24. The high resolution mass spectrum exhibited a molecular ion $(\mathrm{M}=366)$ and fragmentation ions consistent with the spiroacetal structure 24. For example, ions corresponding to the loss of $\mathrm{OCH}_{3}(\mathrm{~m} / \mathrm{z} 335), \mathrm{CH}_{3} \mathrm{OH}(\mathrm{m} / \mathrm{z}, 334),-\mathrm{CH}_{2} \mathrm{CH}_{2} \mathrm{OH}(\mathrm{m} / \mathrm{z}, 321), \mathrm{H}_{2} \mathrm{O}$ and $\mathrm{CH}_{3} \mathrm{OH}(\mathrm{m} / \mathrm{z}, 316)$ and $-\mathrm{CH}_{2} \mathrm{OBn}(\mathrm{m} / \mathrm{z}, 245)$ are prominent, along with ions for oxygenated pyran fragments (eg. $\mathrm{m} / \mathrm{z}, 237){ }^{17,18}$ 


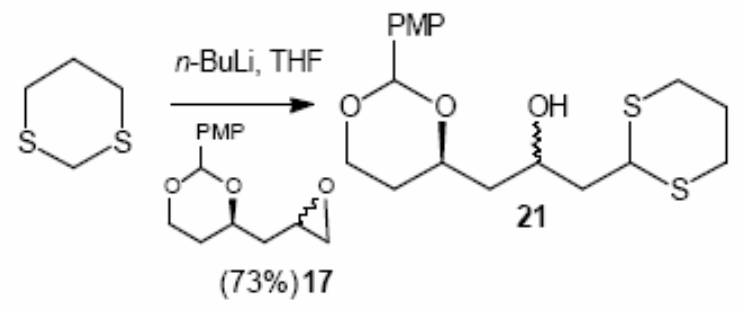

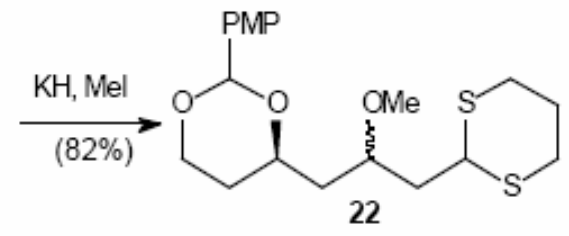
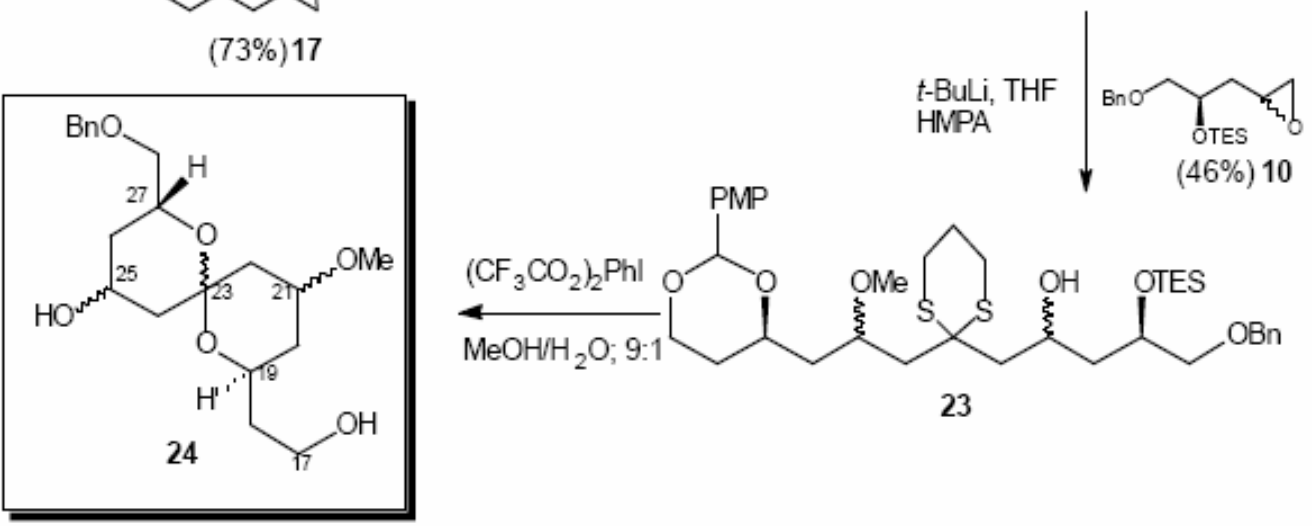

Scheme 3. Synthesis of spiroacetal 24 via dithiane coupling reactions.

This spiroacetal system 24 contains five stereogenic centres, and as two of these (C19 and C27) were installed asymmetrically, there remains the possible formation of eight diastereoisomers. Reverse phase HPLC (acetonitrile/water) successfully separated the diastereomers and sufficient of each was obtained to enable high-field NMR studies, although in some cases, only very small amounts (sub-milligram) were available, and accurate optical rotations could not be determined. Benzene-d6 was employed as solvent to avoid possible acid catalysed equilibration (See Scheme 4) of the purified spiroacetals, a problem encountered previously with simpler systems in choroform. ${ }^{19}$

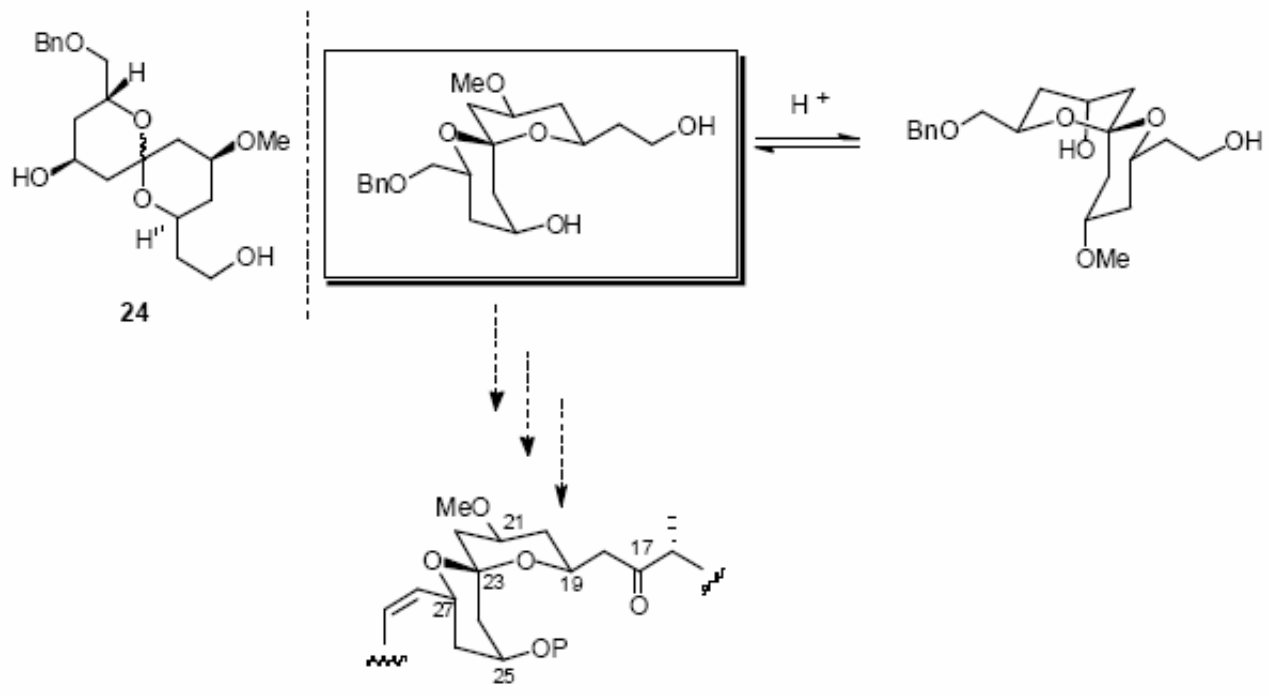

$\mathrm{CD}$ rings of the spongistatin system

Scheme 4. Notional acid catalysed isomerization of spiroacetal 24. 


\section{NMR Analysis of the Stereoisomers}

Seven isomers of spiroacetal system 24 (see Figure 4) were of sufficient purity to allow analysis of the proton and carbon NMR data utilising a combination of high field 1-D and 2-D NMR and nOe analysis (at 400, 500 and $750 \mathrm{MHz}$ ). These isomers are referred to as $\mathbf{A}-\mathbf{G}$ for convenience and ease of comparisons, and are shown in Figure 4, together with the remaining $Z E / E Z$ isomer, $\mathbf{H}$, which was not formed in sufficient amount for separation and NMR identification. It is of interest that the relative amounts of the seven isomers A-G formed under our spiroacetalisation conditions, are comparable, and no isomer predominates over the others by a factor exceeding 4 or 5. Given the difficulties in calculating equilibrium positions in acetal isomerisations, meaningful reconciliation of the data with computed relative free energies is extremely difficult. ${ }^{20}$ Comparative analysis of the proton and carbon shifts (See Tables 1 and 2) reveals a number of characteristic resonances for certain centres in the $Z$, $E$ spiroacetal system that mirror earlier findings on simpler systems. ${ }^{19}$
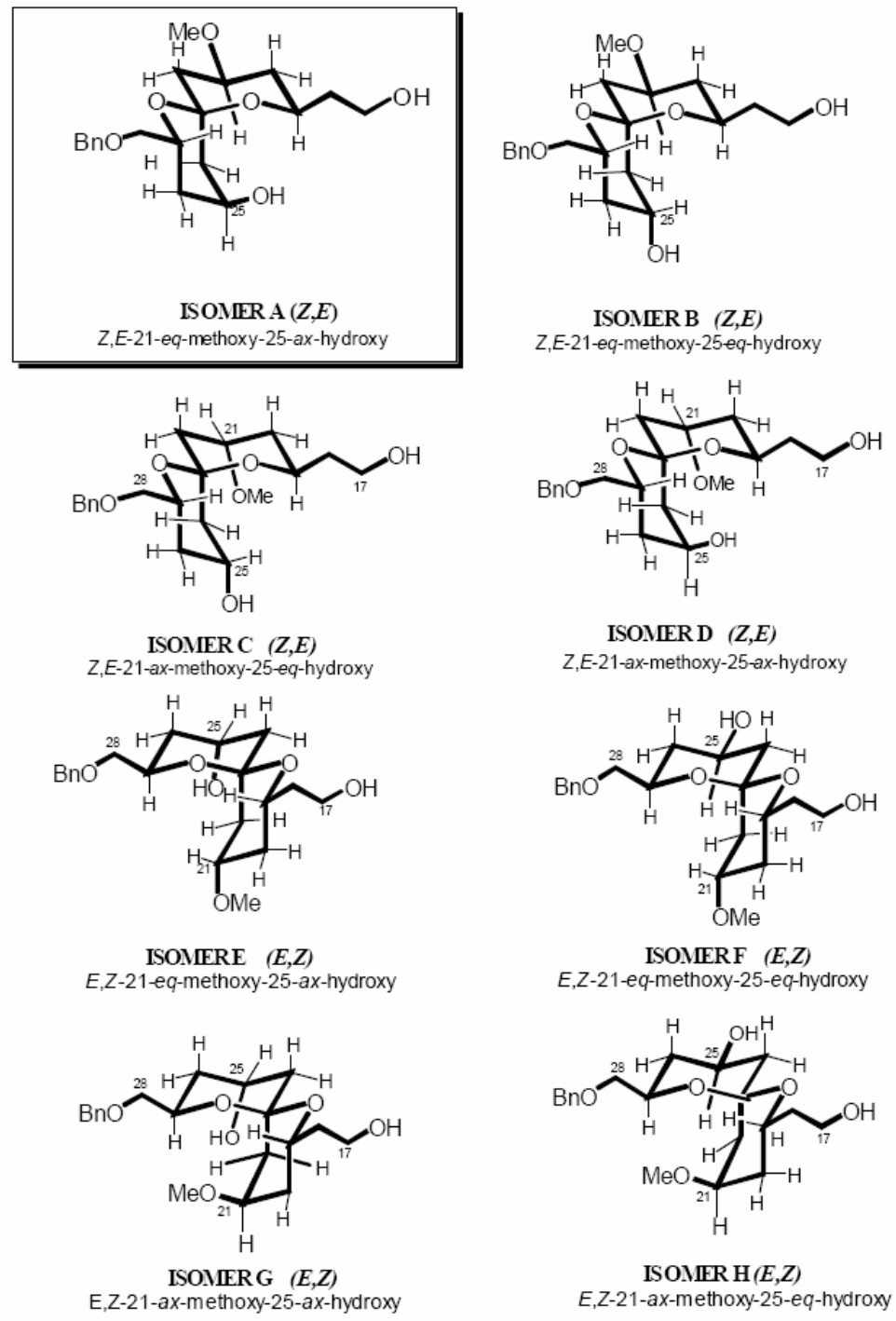

Figure 4. Isomers A-H of spiroacetal system 24 
The ${ }^{1} \mathrm{H}$ and ${ }^{13} \mathrm{C}$ NMR chemical shifts for isomers $\mathbf{A}-\mathbf{G}$ are presented in Tables 1 and 2, and a summary of ${ }^{1} \mathrm{H}$ shifts with coupling patterns and nOe data is given in Table 3.

Table $1{ }^{1} \mathrm{H}$ Chemical shift assignments

\begin{tabular}{|c|c|c|c|c|c|c|c|c|}
\hline Assignment & $\begin{array}{c}\text { Isomer } \\
\text { A } \\
\end{array}$ & $\begin{array}{c}\text { Isomer } \\
\mathbf{B} \\
\end{array}$ & $\begin{array}{c}\text { Isomer } \\
\text { C } \\
\end{array}$ & $\begin{array}{c}\text { Isomer } \\
\text { D } \\
\end{array}$ & $\begin{array}{c}\text { Isomer } \\
\mathbf{E} \\
\end{array}$ & $\begin{array}{c}\text { Isomer } \\
\mathbf{F} \\
\end{array}$ & Isomer $\mathbf{G}$ & $\begin{array}{c}\text { Cinachyrolide } \\
\text { A }^{*}\end{array}$ \\
\hline H17A & 3.52 & 3.48 & 3.60 & 3.60 & 3.60 & 3.60 & 3.65 & \\
\hline H17B & 3.81 & 3.62 & 3.64 & 3.73 & 3.68 & 3.68 & 3.69 & \\
\hline \multirow[t]{2}{*}{ H18A } & $1.43-$ & 1.38 & $1.38-$ & 1.54 & $1.43-$ & 1.44 & $1.45-1.58$ & 2.84 \\
\hline & 1.50 & & 1.52 & & 1.51 & & & \\
\hline \multirow[t]{2}{*}{ H18B } & $1.43-$ & 1.57 & $1.72-$ & 1.74 & $1.55-$ & 1.60 & $1.45-1.58$ & 2.87 \\
\hline & 1.50 & & 1.90 & & 1.63 & & & \\
\hline H19ax & 3.56 & 3.35 & 4.01 & 4.12 & 4.13 & 4.26 & 4.58 & 4.11 \\
\hline \multirow[t]{2}{*}{ H20ax } & 1.15 & 1.15 & $1.38-$ & 1.49 & 1.18 & 1.15 & 1.21 & 1.03 \\
\hline & & & 1.52 & & & & & \\
\hline \multirow[t]{2}{*}{ H20eq } & 1.68 & 1.64 & $1.38-$ & 1.49 & $1.78-$ & 1.81 & 1.59 & 2.01 \\
\hline & & & 1.52 & & 1.88 & & & \\
\hline H21 & 3.09 & 3.16 & 3.38 & 3.42 & 3.69 & 3.58 & 3.22 & 3.57 \\
\hline OMe21 & 3.04 & 3.04 & & 2.96 & 3.13 & 3.11 & 3.12 & \\
\hline \multirow[t]{2}{*}{ H22ax } & 1.70 & 1.70 & $1.72-$ & 1.69 & 1.26 & 1.17 & 1.19 & 1.20 \\
\hline & & & 1.90 & & & & & \\
\hline \multirow[t]{2}{*}{ H22eq } & 2.03 & 2.14 & $1.72-$ & 1.81 & 2.44 & 2.21 & 2.27 & 2.06 \\
\hline & & & 1.90 & & & & & \\
\hline \multirow[t]{2}{*}{ H24ax } & 0.97 & 1.04 & 1.19 & 1.25 & $1.35-$ & 1.55 & $1.33-1.41$ & 1.65 \\
\hline & & & & & 1.40 & & & \\
\hline \multirow[t]{2}{*}{ H24eq } & 1.94 & 2.24 & 2.64 & 2.40 & $1.78-$ & 1.72 & 1.76 & 2.4 \\
\hline & & & & & 1.88 & & & \\
\hline H25 & 3.76 & 3.85 & 3.98 & 3.92 & 3.88 & 3.58 & 3.90 & 4.03 \\
\hline $\mathrm{HO} 25$ & & & & & 2.13 & & & \\
\hline \multirow[t]{2}{*}{ H26ax } & $1.43-$ & 1.32 & 1.26 & 1.40 & $1.35-$ & 1.36 & $1.33-1.41$ & 1.65 \\
\hline & 1.50 & & & & 1.40 & & & \\
\hline \multirow[t]{2}{*}{ H26eq } & 1.58 & 1.90 & $1.72-$ & 1.64 & $1.78-$ & 1.67 & 1.83 & 1.65 \\
\hline & & & 1.90 & & 1.88 & & & \\
\hline H27ax & 4.69 & 4.28 & 4.23 & 4.67 & 4.20 & 3.50 & 4.24 & 5.1 \\
\hline $\mathrm{H} 28 \mathrm{~A}$ & 3.41 & 3.38 & 3.33 & 3.36 & 3.38 & 3.30 & 3.55 & 5.4 \\
\hline H28B & 3.47 & 3.46 & 3.45 & 3.45 & 3.60 & 3.45 & 3.64 & \\
\hline
\end{tabular}

Note: The equatorial and axial protons on the carbon adjacent to the spiro centre in the $\mathrm{E}$ ring of the $Z E / E Z$ system 24 are displaced markedly down- and up-field respectively. 
Table 2. ${ }^{13} \mathrm{C}$ Chemical Shift Assignments

\begin{tabular}{cccccc}
\hline Assignment & Isomer $\mathbf{B}$ & Isomer $\mathbf{C}$ & Isomer $\mathbf{D}$ & Isomer $\mathbf{E}$ & Isomer $\mathbf{F}$ \\
\hline C17 & 60.10 & 60.60 & 59.80 & 60.05 & 60.30 \\
C18 & 39.00 & 38.90 & 38.80 & 39.02 & 38.80 \\
C19 & 69.00 & 68.50 & 68.20 & 67.87 & 68.40 \\
C20 & 38.10 & 35.40 & 35.00 & 37.99 & 37.90 \\
C21 & 74.20 & 23.10 & 72.50 & $73.00^{*}$ & 64.40 \\
C22 & 42.90 & 39.80 & 40.80 & 42.00 & 44.40 \\
C23 & 100.20 & 99.80 & 99.10 & 99.92 & 99.60 \\
C24 & 39.40 & 42.70 & 38.00 & $34.94^{* *}$ & 38.50 \\
C25 & 64.20 & 64.50 & 64.60 & 61.69 & 72.80 \\
C26 & 38.50 & 38.00 & 35.10 & $44.69 * *$ & 36.40 \\
C27 & 69.60 & 69.20 & 64.70 & 70.68 & 70.50 \\
C28 & 73.63 & 73.90 & 74.00 & 72.62 & 73.50 \\
OMe & 55.30 & 55.80 & 55.50 & 55.13 & 55.10 \\
ArCH2O & 73.61 & 73.50 & 73.30 & $73.04^{*}$ & 73.20 \\
Ar & 127.80 & & 127.76 & 127.85 & 127.88 \\
Ar & 128.10 & & 128.13 & 128.12 & $127.24(3 C)$ \\
Ar & 128.30 & & 128.48 & 128.61 & 128.59 \\
Ar & $128.5(2 \mathrm{C})$ & & 139.00 & 138.96 & 139.06 \\
Ar & 128.70 & & & & \\
\hline Aster & & & &
\end{tabular}

Asterisked shifts may be interchangeable.

Table 3

\begin{tabular}{|c|c|c|c|}
\hline Isomer $\mathbf{A}$ & & & \\
\hline Proton shift & Assignment & Coupling pattern & nOe Correlations \\
\hline 3.52 & H17A & $\mathrm{m}$ & \\
\hline 3.81 & H17B & $\mathrm{m}$ & \\
\hline $1.43-1.50$ & H18A & m, overlap with H18B and H26ax & \\
\hline $1.43-1.50$ & H18B & m, overlap with H18A and H26ax & \\
\hline 3.56 & H19ax & $\mathrm{m}$ & H24eq, H18A\&B, H20eq \\
\hline 1.15 & H20ax & ddd, $J=11.6,11.6,11.6 \mathrm{~Hz}$ & \\
\hline 1.68 & H20eq & m, overlap with H22ax & \\
\hline 3.09 & H21ax & $\mathrm{m}$ & H24eq, H22eq, H20eq \\
\hline 3.04 & OMe21 & s, $3 \mathrm{H}$ & \\
\hline \multirow[t]{2}{*}{1.70} & H22ax & dd, $J \sim 12.2,12.2 \mathrm{~Hz}$ overlap with & \\
\hline & & H20eq & \\
\hline 2.03 & H22eq & ddd, $J=12.4,4.5,1.65 \mathrm{~Hz}$ & \\
\hline 0.97 & H24ax & dd, $J=14.6,3.68 \mathrm{~Hz}$ & \\
\hline
\end{tabular}


Table 3. Continued

\begin{tabular}{|c|c|c|c|}
\hline 1.94 & H24eq & dm, J 14.7, 4.3, $1.8 \mathrm{~Hz}$ & H19ax, H21ax, H25eq \\
\hline \multirow[t]{2}{*}{3.76} & H25eq & $\mathrm{m}$ & H24ax\&eq, H26ax\&eq \\
\hline & $\mathrm{HO} 25$ & & \\
\hline $1.43-1.50$ & H26ax & m, overlap with H18A and H18B & \\
\hline 1.58 & H26eq & $\mathrm{dm}, J \sim 12 \mathrm{~Hz}$ & \\
\hline 4.69 & H27ax & $\mathrm{m}$ & H26eq \\
\hline 3.41 & H28A & dd, $J=9.9,4.95 \mathrm{~Hz}$ & \\
\hline 3.47 & H28B & dd, $J=9.8,4.80 \mathrm{~Hz}$ & \\
\hline \multicolumn{4}{|l|}{ Isomer $\mathbf{B}$} \\
\hline Proton shift & Assignment & Coupling Pattern & nOe effects \\
\hline 3.48 & H17A & $\mathrm{m}$ & \\
\hline 3.62 & H17B & $\mathrm{m}$ & \\
\hline 1.38 & H18A & $\mathrm{m}$ & \\
\hline 1.57 & H18B & $\mathrm{m}$ & \\
\hline 3.35 & H19ax & $\mathrm{m}$ & H18A\&B, H24eq, H25, H21 \\
\hline 1.15 & H20ax & ddd, $J=11.7,11.7,11.7 \mathrm{~Hz}$ & \\
\hline 1.64 & H20eq & dm, $J \sim 12.4, \sim 1.9 \mathrm{~Hz}$ & \\
\hline 3.16 & H21ax & $\mathrm{m}$ & H19, H20eq, H22eq, H24eq \\
\hline 3.04 & OMe21 & s, $3 \mathrm{H}$ & \\
\hline 1.70 & H22ax & $\mathrm{dd}, J \sim 12.2,11.7 \mathrm{~Hz}$ & \\
\hline 2.14 & H22eq & ddd, $J=12.4,4.6,1.8 \mathrm{~Hz}$ & \\
\hline 1.04 & H24ax & dd, $J=13,11.4 \mathrm{~Hz}$ & \\
\hline 2.24 & H24eq & ddd, $J \sim 12.9,4.3,1.8 \mathrm{~Hz}$ & H19, H21, H25 \\
\hline \multirow[t]{2}{*}{3.85} & $\mathrm{H} 25 \mathrm{ax}$ & $\mathrm{m}$ & H27, H19, H24 eq, H26eq \\
\hline & HO25 & & \\
\hline 1.32 & H26ax & ddd, $J=11.9,11.9,11.9 \mathrm{~Hz}$ & \\
\hline 1.90 & H26eq & dm, J 12.2, $2.1 \mathrm{~Hz}$ & \\
\hline 4.28 & H27ax & $\mathrm{m}$ & H25, H26eq, H28A\&B \\
\hline 3.38 & H28A & $\mathrm{dd}, J=9.8,5.1 \mathrm{~Hz}$ & \\
\hline 3.46 & H28B & $\mathrm{dd}, J=9.8,5.1 \mathrm{~Hz}$ & \\
\hline \multicolumn{4}{|l|}{ Isomer $\mathbf{C}$} \\
\hline Proton shift & Assignment & Coupling pattern & nOe Effects \\
\hline 3.60 & H17A & m (app. Quintet) & \\
\hline 3.64 & H17B & $\mathrm{m}, \mathrm{br}$ & \\
\hline \multirow[t]{2}{*}{$1.38-1.52$} & H18A & m, superimposed on H20ax \& & \\
\hline & & H20eq & \\
\hline \multirow[t]{2}{*}{$1.72-1.90$} & H18B & m, superimposed on H22ax \& & \\
\hline & & H22eq \& H26eq & \\
\hline 4.01 & H19ax & $\mathrm{m}$ & H24eq, H18A\&B, \\
\hline ISSN 1424-6376 & & Page 123 & ${ }^{\circ}$ ARKAT USA, Inc \\
\hline
\end{tabular}


Table 3. Continued

\begin{tabular}{|c|c|c|c|}
\hline $1.38-1.52$ & H20ax & m, superimposed on H18A \& H20eq & \\
\hline $1.38-1.52$ & H20eq & m, superimposed on H18A \& H20ax & \\
\hline \multirow[t]{2}{*}{3.38} & H21eq & m, app quintet $J=4.2 \mathrm{~Hz}$ & H20eq\&ax, H22eq\&ax \\
\hline & OMe21 & & \\
\hline \multirow[t]{2}{*}{$1.72-1.90$} & H22ax & m, superimposed on H18B \& H22eq & \\
\hline & & \& H26eq & \\
\hline \multirow[t]{2}{*}{$1.72-1.90$} & H22eq & m, superimposed on H18B \& H22ax & \\
\hline & & \& H26eq & \\
\hline 1.19 & H24ax & & \\
\hline 2.64 & H24eq & $\mathrm{dm}, J \sim 13.1 \mathrm{~Hz}$ & H19 \\
\hline \multirow[t]{2}{*}{3.98} & H25ax & $\mathrm{M}$ & H24eq, H27, H19 \\
\hline & $\mathrm{HO} 25$ & & \\
\hline 1.26 & H26ax & & \\
\hline \multirow[t]{2}{*}{$1.72-1.90$} & H26eq & m, superimposed on H18B \& H22ax & \\
\hline & & \& H22eq & \\
\hline 4.23 & H27ax & M & H25, H28A\&B \\
\hline 3.33 & H28A & $\mathrm{dd}, J=9.9,4.4 \mathrm{~Hz}$ & \\
\hline 3.45 & H28B & dd, $J=9.9,5.7 \mathrm{~Hz}$ & \\
\hline \multicolumn{4}{|l|}{ Isomer $\mathbf{D}$} \\
\hline Proton Shift & Assignment & Coupling Pattern & nOe effects \\
\hline 3.60 & H17A & M & \\
\hline 3.73 & H17B & M & \\
\hline 1.54 & $\mathrm{H} 18 \mathrm{~A}$ & M & \\
\hline 1.74 & H18B & M & \\
\hline 4.12 & H19ax & M & H24eq, H18A\&B, H20eq \\
\hline 1.49 & H20ax & m, superimposed on H20eq & \\
\hline 1.49 & H20eq & m, superimposed on H20ax & \\
\hline 3.42 & H21eq & $\mathrm{M}$ & H20ax\&eq, H22ax\&eq \\
\hline 2.96 & 21OMe & $\mathrm{S}$ & \\
\hline 1.69 & H22ax & $\mathrm{dd}, J=13.7,5 \mathrm{~Hz}$ & \\
\hline 1.81 & H22eq & dd, $J=13.7,4.4 \mathrm{~Hz}$ & \\
\hline 1.25 & H24ax & dd, $J=14.7,3.6 \mathrm{~Hz}$ & \\
\hline 2.40 & H24eq & $\mathrm{dt}, J=14.8,2.3,2.3 \mathrm{~Hz}$ & H19ax, H25eq, H24ax \\
\hline \multirow[t]{2}{*}{3.92} & H25eq & narrow $\mathrm{m}$ & H24eq\&ax, H26ax\&eq ) \\
\hline & $25 \mathrm{OH}$ & & \\
\hline 1.40 & H26ax & td, $J=12.7,2.9 \mathrm{~Hz}$ & \\
\hline 1.64 & H26eq & $\mathrm{dm}, J=13 \mathrm{~Hz}$ & \\
\hline 4.67 & H27ax & $\mathrm{M}$ & H26eq\&ax, H28A\&B \\
\hline 3.36 & H28A & $\mathrm{AB}$ of $\mathrm{ABX}, J=10,4.2 \mathrm{~Hz}$ & \\
\hline ISSN 1424-6376 & & Page 124 & ${ }^{\circ}$ ARKAT USA, Inc \\
\hline
\end{tabular}


Table 3. Continued

\begin{tabular}{|c|c|c|c|}
\hline 3.45 & H28B & $\mathrm{AB}$ of $\mathrm{ABX}, J=10,5.8 \mathrm{~Hz}$ & \\
\hline 4.36 & $\mathrm{ArCH}_{2} \mathrm{O}$ & s, superimposed & \\
\hline 4.36 & $\mathrm{ArCH}_{2} \mathrm{O}$ & s, superimposed & \\
\hline 7.04-7.61 & Aromatics x 5 & M & \\
\hline \multicolumn{4}{|l|}{ Isomer $\mathbf{E}$} \\
\hline Proton shift & Assignment & Coupling pattern & nOe effects \\
\hline 3.60 & H17A & m, superimposed on H28B & \\
\hline 3.68 & H17B & M & \\
\hline $1.43-1.51$ & H18A & M & \\
\hline $1.55-1.63$ & H18B & M & \\
\hline 4.13 & H19ax & m, app. Tq & H21, H18, H20eq \\
\hline 1.18 & H20ax & br q, J 11.55 Hz & \\
\hline $1.78-1.88$ & H20eq & m, overlap with H26eq, H24eq & \\
\hline 3.69 & H21ax & $\mathrm{tt}, J=11.2,4.4 \mathrm{~Hz}$ & H19, H27, H22eq \\
\hline 3.13 & 21OMe & $\mathrm{S}$ & \\
\hline 1.26 & H22ax & $\mathrm{dd}, J=12.7,11.35 \mathrm{~Hz}$ & H24eq, H20ax \\
\hline 2.44 & H22eq & ddd, $J=12.7,4.4,2.0 \mathrm{~Hz}$ & \\
\hline $1.35-1.40$ & H24ax & m, superimposed on H26ax & H25 \\
\hline $1.78-1.88$ & H24eq & m, overlap with H20eq, H26eq & H25 \\
\hline 3.88 & H25eq & $\mathrm{M}$ & H24ax/H26ax, H24eq/H26eq \\
\hline 2.13 & $25 \mathrm{OH}$ & & \\
\hline $1.35-1.40$ & H26ax & m, superimposed on H24ax & H25 \\
\hline $1.78-1.88$ & H26eq & m, overlap with H20eq, H24eq & H25 \\
\hline 4.20 & H27ax & m, app. Quintet & \\
\hline 3.38 & H28A & $\mathrm{AB}$ of $\mathrm{ABX}, J=9.9,6.2 \mathrm{~Hz}$ & \\
\hline 3.60 & H28B & $\mathrm{M}$ & \\
\hline 4.38 & $\mathrm{ArCH}_{2} \mathrm{O}$ & $\mathrm{AB} J A B=12.3$ & \\
\hline 4.42 & $\mathrm{ArCH}_{2} \mathrm{O}$ & $\mathrm{AB} J A B=12.3$ & \\
\hline 7.11-7.31 & Aromatics $x 5$ & M & \\
\hline \multicolumn{4}{|l|}{ Isomer $\mathbf{F}$} \\
\hline Proton shift & Assignment & Coupling Pattern & nOe effects \\
\hline 3.60 & H17A & $\mathrm{m}$ & \\
\hline 3.68 & H17B & $\mathrm{m}$ & \\
\hline 1.44 & H18A & $\mathrm{m}$ & \\
\hline 1.60 & H18B & $\mathrm{m}$ & \\
\hline 4.26 & H19ax & $\mathrm{m}$ & H20eq, H18A, H21 \\
\hline 1.15 & H20ax & $\begin{array}{c}\text { br q, } J \sim 11.9 \mathrm{~Hz} \text { (overlap } \\
\text { withH24ax) }\end{array}$ & \\
\hline
\end{tabular}


Table 3. Continued

\begin{tabular}{|c|c|c|c|}
\hline 1.81 & H20eq & $\begin{array}{c}\mathrm{dm}, J \sim 12 \mathrm{~Hz}+\text { small } \\
\text { coupling } 2.3 \mathrm{~Hz}\end{array}$ & \\
\hline 3.58 & H21ax & m, superimposed on H25 & \\
\hline 3.11 & 21OMe & s & \\
\hline 1.17 & H22ax & dd, $J=12.8,11.3 \mathrm{~Hz}$ (overlap with & \\
\hline & & $\left.\mathrm{H} 2 \mathrm{O}_{\mathrm{ax}}\right)$ & \\
\hline 2.21 & H22eq & $\begin{array}{c}\text { ddd, } J=12.8,4.4,1.9 \mathrm{~Hz} \mathrm{H} 27 \text {, } \\
\text { H21/H25 }\end{array}$ & \\
\hline \multicolumn{4}{|l|}{1.55 H24ax dd, } \\
\hline \multicolumn{4}{|l|}{$J=13.0,8.2 \mathrm{~Hz}$} \\
\hline 1.72 & H24eq & ddd, $J=12.9,4.9, \sim 1 \mathrm{~Hz}$ & \\
\hline 3.58 & H25ax & m, superimposed on H21 & \\
\hline \multicolumn{4}{|l|}{$25 \mathrm{OH}$} \\
\hline 1.36 & H26ax & ddd, $J \sim 12,12,12 \mathrm{~Hz}$ & \\
\hline 1.67 & H26eq & $\mathrm{dm}, J \sim 12 \mathrm{~Hz}$ & \\
\hline 3.50 & H27ax & br m & H22eq, H26eq, H25 \\
\hline 3.30 & $\mathrm{H} 28 \mathrm{~A}$ & AB of $\mathrm{ABX}, J=9.9,4.4 \mathrm{~Hz}$ & \\
\hline 3.45 & H28B & $\mathrm{AB}$ of $\mathrm{ABX}, J=9.8,5.9 \mathrm{~Hz}$ & \\
\hline 4.4 & $\mathrm{ArCH}_{2} \mathrm{O}$ & $\mathrm{AB} \mathrm{JAB} \sim 12 \mathrm{~Hz}$ & \\
\hline 4.4 & $\mathrm{ArCH}_{2} \mathrm{O}$ & $\mathrm{AB} \mathrm{JAB} \sim 12 \mathrm{~Hz}$ & \\
\hline 7.11-7.41 & Aromatics $\mathrm{x} 5$ & $\mathrm{~m}$ & \\
\hline \multicolumn{4}{|l|}{ Isomer $\mathbf{G}$} \\
\hline Proton shift & Assignment & Coupling pattern & nOe effects \\
\hline 3.65 & H17A & $\mathrm{m}$ & \\
\hline 3.69 & H17B & m (app. Sextet) & \\
\hline $1.45-1.58$ & $\mathrm{H} 18 \mathrm{~A}$ & m, superimposed on H18B & \\
\hline $1.45-1.58$ & H18B & m, superimposed on H18A & \\
\hline 4.58 & H19ax & br m, & $J \sim 14 \mathrm{~Hz}+$ small coupling \\
\hline 1.21 & H20ax & br t, $J \sim 14 \mathrm{~Hz}$ & \\
\hline 1.59 & H20eq & br d, J 13.5 Hz & \\
\hline 3.22 & H21eq & app. quintet $J=3.4,3.4,3.4,3.4 \mathrm{~Hz}$ & H22ax\&eq, H20ax\&eq \\
\hline 3.12 & 21OMe & s & \\
\hline 1.19 & H22ax & $\mathrm{dd}, 15.5,3.8 \mathrm{~Hz}$ & \\
\hline 2.27 & H22eq & ddd, $J=15.4,2.2,3.0 \mathrm{~Hz}$ & H27 \\
\hline $1.33-1.41$ & $\mathrm{H} 24 \mathrm{ax}$ & m, superimposed on H26ax & \\
\hline 1.76 & H24eq & ddd, $J=13.0,4.5,1.0 \mathrm{~Hz}$ & \\
\hline 3.90 & H25eq & m, app. Octet, coupled to $\mathrm{OH}$ also & H24ax\&eq and H26ax\&eq \\
\hline \multicolumn{4}{|l|}{$25 \mathrm{OH}$} \\
\hline $1.33-1.41$ & H26ax & m, superimposed on H24ax & \\
\hline
\end{tabular}


Table 3. Continued

\begin{tabular}{llcl}
\hline 1.83 & H26eq & br dt, $J=13.7,5.3,5.3 \mathrm{~Hz}$ & H22eq \\
4.24 & H27ax & m, app. Quintet, $J=6 \mathrm{~Hz}$ & \\
3.55 & H28A & AB of ABX, $J=9.8,7.0 \mathrm{~Hz}$ & \\
3.64 & H28B & AB of ABX, $J=9.8,5.35 \mathrm{~Hz}$ &
\end{tabular}

\section{Stereochemical Assignments}

High field nOe studies were used to assign the configurations of the isomers $\mathbf{A}-\mathbf{G}$, with emphasis on the relative configuration of the CD ring and the axial or equatorial orientations of the methoxy and hydroxy groups at C21 and C25 respectively. None of the isomers A-G appeared to favour a conformation in which either of the benzyloxymethyl or $2 \mathrm{~N}$-hydroxyethyl groups was predominantly axially orientated.

Isomer A: Z,E-(19R,21S, 23S,25S,27R)-24. Examination of the spectra of isomer A confirmed its stereochemical correlation with the natural CD spiroacetal fragment. ${ }^{21}$ Specifically the CD ring configuration was assigned as Z,E with the C21 methoxy and C25 hydroxy groups concluded to be equatorially and axially disposed respectively, based on observed nOe's. (The Z $\mathrm{OH}$ or $\mathrm{E}$ nature of ring $\mathrm{C}$ (that bears the methoxy group) is always given first.) A strong nOe between the equatorial proton on C24 and the C19 proton together with the downfield shift of the C27 proton relative to the C19 proton (due to the deshielding 1,3-syn interaction with the axial $\mathrm{C}-\mathrm{O}$ bond of ring $\mathrm{C})^{19}$ strongly supported the $Z, E$ configuration for the $\mathrm{CD}$ ring system.

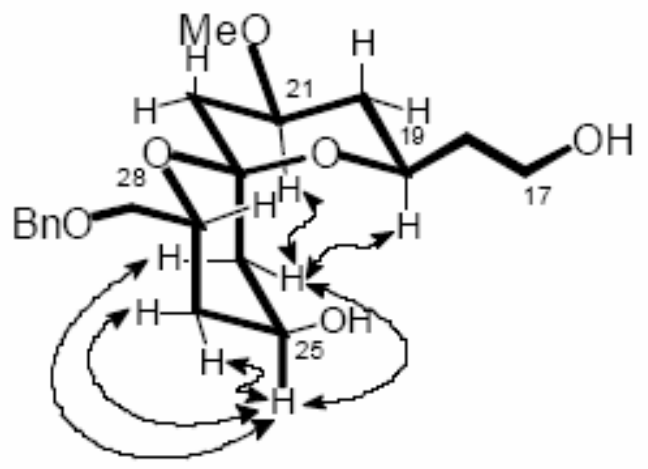

\section{Isomer A}

The C21 methoxy group was equatorially oriented on the basis of the cross ring nOe's of the C21 proton and the equatorial proton on C24 and lack of any nOe's to the adjacent ring protons at C20 and C22. In constrast, the hydroxyl substituent on C25 was disposed axially because nOe's are detected between the C25 proton and adjacent axial and equatorial protons on C24 and C26, but not detected to either C19 or C27 (ie. no diaxial interaction or cross ring proximity).

These stereochemical assignments for $\mathbf{A}$ were consistent with the patterns of proton-proton coupling, interpreted with the aid of 2D COSY and HSQC experiments. The analyses that follow for the isomers $\mathbf{B}$ through $\mathbf{G}$ provided cohesive and consistent sets of assignments and are based 
on the types of interpretations outlined above.

Isomer B: Z,E-(19R,21S,23S,25R,27R)-24. Analyses of spectra of isomer $\mathbf{B}$ identified the same strong nOe between a proton on C24 and C19 as for Isomer A. When considered with the downfield shift of the proton on $\mathrm{C} 27$ relative to the $\mathrm{C} 19$ proton, the assignment of the CD ring system as $Z, E$ configured is strongly indicated.

The C21 methoxy was assigned as equatorial, from the cross ring nOe of its geminal proton to the equatorial C24 proton, and absence of nOe's to adjacent protons. Similarly, the C25 hydroxy substituent was also assigned as equatorial, based on observed diaxial and cross ring nOe's of H25 with protons on C27 (not indicated on accompanying structure) and C19, respectively.

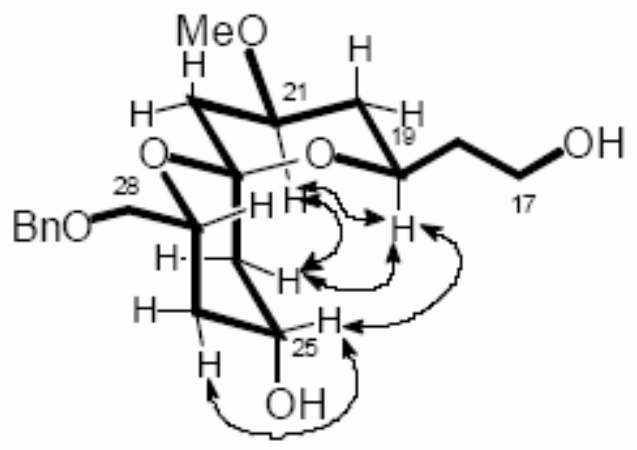

\section{Isomer B}

Isomer C: Z,E-(19R,21R,23S,25R,27R)-24. The spectra of isomer C exhibited the characteristic nOe between the protons on C24 and C19, and the downfield shift of the proton on $\mathrm{C} 27$ relative to the $\mathrm{C} 19$ proton, as in isomers $\mathbf{A}$ and $\mathbf{B}$. Consequently the $\mathrm{CD}$ ring was designated as Z,E. The C21 methoxy group was deemed to be axially oriented from the nOe's of its geminal proton to adjacent axial and equatorial protons on C20 and C22 and absence of nOe's to either C19 or C24 (ie. no diaxial interaction or cross ring proximity). The observed diaxial and cross ring nOe's of the C25 proton to the C27 (not shown) and C19 protons respectively, supported assignment of the C25 hydroxyl substituent as equatorial.

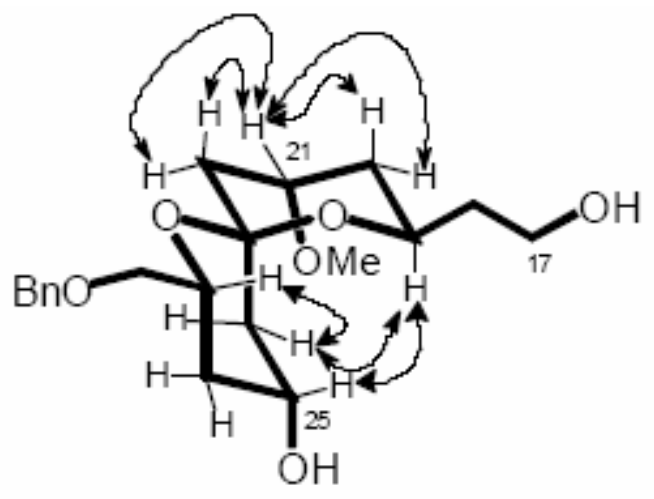

\section{Isomer $\mathbf{C}$}


Isomer D: Z,E-(19R,21R,23S,25S,27R)-24. The Z,E nature of the CD ring system of isomer D was also based upon the presence of a strong nOe between the equatorial proton on C24 and the C19 proton, together with the downfield shift of the proton on C27 relative to the C19 proton, as described above for isomers $\mathbf{A}, \mathbf{B}$ and $\mathbf{C}$. As with Isomer $\mathbf{C}$, the $\mathrm{C} 21$ methoxy was concluded to be axial because of the nOe's between its geminal proton (H21) and adjacent axial and equatorial protons on C20 and C22 rather than with either C19 or C24 (ie. no diaxial interaction or cross ring proximity). The C25 Isomer $\mathbf{D}$ hydroxyl was assigned as axial from the observed nOe's between the C25 proton and adjacent axial and equatorial protons on C24 and C26.

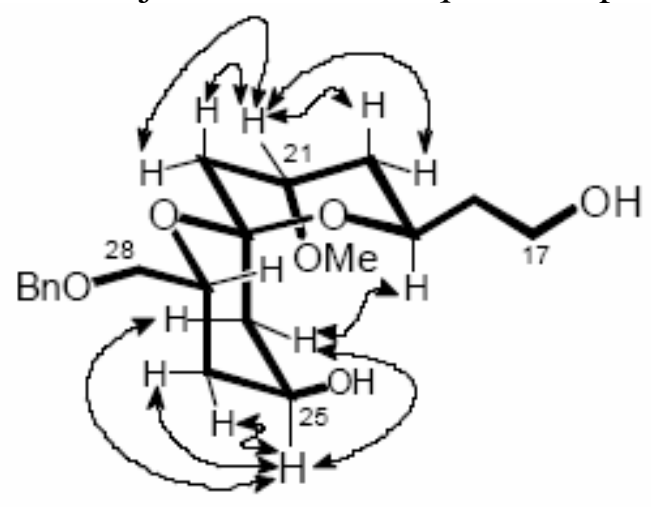

Isomers $\mathbf{E}, \mathbf{F}$ and $\mathbf{G}$ are located in the alternative $E, Z$ system (for the $\mathrm{C}$ and $\mathrm{D}$ rings respectively), and again considerations of nOe's, chemical shifts and coupling patterns lead to the stereochemical conclusions for these isomers. These are not discussed in detail, but the important nOe's are shown on the structures below, and full listings of NMR data are presented in the Tables.

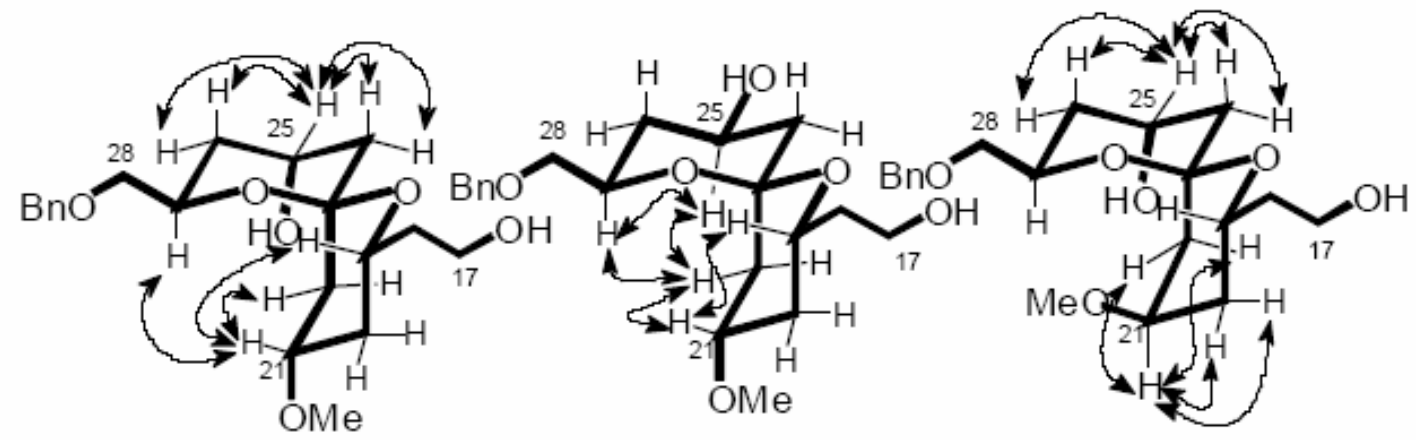

Isomer $\mathbf{E}$

Isomer $\mathbf{F}$

Isomer $\mathbf{G}$

\section{Conclusions}

Seven of the eight possible isomers of the $(Z, E)(E, Z)$ spiroacetal system representing the CD fragment (C17-C28) of spongistatin 1 incuding the one whose stereochemistry correlates with 
the natural fragment, have been characterised by high- field NMR measurements. These provide useful sets of comparison data for this system and similar oxygenated spiroacetal sub-structures. Stereocontrol at C19 and C27 was incorporated using Brown's allylation methodology. The Sharpless asymmetric dihydroxylation procedure has been explored as a vehicle for the introduction of further stereocontrol. For example, incorporation of epoxide $\mathbf{2 0}$ into the general scheme would control the configuration at C21, and similarly, control at C25 could be enforced.

\section{Experimental Section}

General Procedures. All operations involving air-sensitive reagents were performed under an inert atmosphere using syringe and cannula techniques. Glassware was assembled hot, evacuated and purged with nitrogen. THF and ether were distilled under nitrogen from sodium benzophenone ketyl. DCM was distilled from calcium hydride. ${ }^{1} \mathrm{H}$ and ${ }^{13} \mathrm{C}$ NMR spectra were recorded at the frequencies stated on a Bruker DMX750, AMX500, AMX400 or AC200F NMR spectrometer. Unless otherwise stated all ${ }^{1} \mathrm{H}$ NMR spectra were referenced to residual $\mathrm{CHCl}_{3}(\delta$ 7.24) and all ${ }^{13} \mathrm{C}$ NMR spectra were referenced to the central component of the $\mathrm{CDCl}_{3}$ triplet at $\delta$ 77.0. $750 \mathrm{MHz}{ }^{1} \mathrm{H}$ and $187 \mathrm{MHz}{ }^{13} \mathrm{C}$ spectra were obtained on sub-milligram samples using NMR microtubes purchase from the Aldrich chemical company. Reverse phase HPLC was performed on a Dynamax 60A C18 column. GC-MS analyses were carried out on a Hewlett Packard HP5890 GC using a 30mx0.25mm BP5 column and a HP5970 mass selective detector. High resolution mass spectra were obtained from a Kratos MS25RFA instrument. Optical rotations were measured on a Perkin-Elmer 241 MC polarimeter using the sodium D line (589nm).

2-Benzyloxyethanal (6) was prepared from the bis-benzyl ether of 2-butene-1,4- diol 5 as described elsewhere. ${ }^{15}$ The product was purified by flash chromatography (silica; 30\% EtOAc in hexane) to provide the required aldehyde 6, (9.5 g, 93\%). ${ }^{1} \mathrm{H} \mathrm{NMR}:\left(\mathrm{CDCl}_{3} 200 \mathrm{MHz}\right) \delta 4.09$ (s, 2H), 4.62 (s, 2H), 7.35 (m, 5H), 9.35 (s, 1H). ${ }^{13} \mathrm{C}$ NMR: 73.60, 75.20, 128.00 (2C), 128.17, 128.55 (2C), 136.73, 200.43 (CHO).

Bis-(2-isocarenyl)-allylborane (7). To a cooled $\left(-10^{\circ} \mathrm{C}\right)$ and stirred solution of boranedimethylsulfide complex (10 mL, $100 \mathrm{mmol})$ in dry THF (200 mL) under nitrogen, 2-carene ( $30 \mathrm{~g}, 200 \mathrm{mmol}$ ) was added dropwise with the solution maintained at $-10^{\circ} \mathrm{C}$ throughout the addition. The reaction mixture was then stored at $0^{\circ} \mathrm{C}$ for $24 \mathrm{~h}$, and the product appeared as white needles. The THF was decanted using a cannula and the solid was washed with cold ether $\left(0^{\circ} \mathrm{C}, 3 \times 100 \mathrm{~mL}\right)$ with the exclusion of air, and then dried under vacuum $(1 \mathrm{mbar}, 1 \mathrm{~h})$. This bis-(2-isocarenyl)borane hydride (12.39 g, $43.3 \mathrm{mmol}$ ) was then transferred (glove-bag) into a dry, round bottomed flask and ether $(17 \mathrm{~mL})$ was added and the mixture stirred at $0^{\circ} \mathrm{C}$. Dry methanol (spectrometric grade, $3 \Delta$ sieves) $(3.6 \mathrm{~mL}$ ) was introduced dropwise over 10 minutes, after which the reaction mixture was stirred for a further $3 \mathrm{~h}$ at $0^{\circ} \mathrm{C}$. The solvent and excess 
methanol were then evaporated (1 mmbar, 3 hours). After diluting with dry ether $(17 \mathrm{~mL})$, the reaction mixture was cooled to $-78^{\circ} \mathrm{C}$ and allyl magnesium bromide $(41.5 \mathrm{~mL}, 1.0 \mathrm{M}, 41.5$ mmol) was added dropwise from a pressure equalising dropping funnel. The reaction mixture was stirred for a further 15 minutes at $-78^{\circ} \mathrm{C}$ and then for $1 \mathrm{~h}$ at room temperature. The product was used immediately.

(R)-5-benzyloxy-4-hydroxypentene (8). Aldehyde 6 (1.62 g, $10.77 \mathrm{mmol}$ ) was dissolved in precooled $\left(-78^{\circ} \mathrm{C}\right)$ dry ether, and added via cannula to freshly prepared allyl borane 7 cooled to $-78^{\circ} \mathrm{C}$. After 2 hours at $-78^{\circ} \mathrm{C}$, the reaction was quenched with $3 \mathrm{~N} \mathrm{NaOH}(5 \mathrm{~mL})$ followed by $10 \mathrm{~mL}$ of $30 \%$ aq. $\mathrm{H}_{2} \mathrm{O}_{2}$ and left in the freezer overnight. After a further $2-3 \mathrm{~h}$ of reflux, the organic layer was separated, and the aqueous layer extracted after treatment with brine. The organic layer was dried $\left(\mathrm{MgSO}_{4}\right)$ then purified by flash chromatography (silica; 20\% EtOAc in hexane) to provide the desired product $8(1.22 \mathrm{~g}, 61.5 \%)$. [ $\alpha]_{\mathrm{D}}{ }^{23}-1.8$ (c, 2.4, $\left.\mathrm{Et}_{2} \mathrm{O}\right)$. (95\% ee by Mosher ester analysis). GC/MS: m/z $192\left(\mathrm{M}^{+}\right), 174$ (2\%). 151 (2), 139 (2), 107 (8), 105 (8), 92 (22), 91 (100). ${ }^{1} \mathrm{H}$ NMR: (CDCl3, $\left.200 \mathrm{MHz}\right) \mathrm{d}$ 7.37-732 (m, 5H), 5.90-5.77 (m, 1H), 5.16-5.08 (m, 2H), 4.56 (s, 2H), 3.94-3.85 (m, 1H), 3.55-3.51 (dd, $J=10,3.7 \mathrm{~Hz}, 1 \mathrm{H}), 3.41-3.36$ (dd, $J=$ 9.7, $7.4 \mathrm{~Hz}, 1 \mathrm{H}), 2.37$ (d, $J=3.5 \mathrm{~Hz}, 1 \mathrm{H}), 2.28$ (t, $J=6.6 \mathrm{~Hz}, 2 \mathrm{H}) .{ }^{13} \mathrm{C} \mathrm{NMR:}\left(\mathrm{CDCl}_{3}, 50 \mathrm{MHz}\right)$ d 134.21, 132.24, 129.84, 128.21, 127.21, 123.21, 74.01, 73.82, 69.86. 38.72. HRMS: $\mathrm{C}_{12} \mathrm{H}_{16} \mathrm{O}_{2} \mathrm{Na}$ requires 215.1048. Measured, 215.1049.

1-Benzyloxy-4,5-epoxypentan-2-ol (9). To the alkene 8 (1.0 g, $5.2 \mathrm{mmol}$ ), stirred in DCM (10 $\mathrm{mL}$ ) at room temperature, was added mCPBA (2.2 g of a 60\% mixture, 1.5 equivs), in one portion. The reaction was monitored by TLC (silica, 50\% EtOAc in hexane; anisaldehyde) and after $5 \mathrm{~h}$ a further $0.5 \mathrm{~g}$ of $m \mathrm{CPBA}$ was added. Stirring was continued for an hour after which time the reaction was quenched by the addition of saturated $\mathrm{NaHCO}_{3}$ solution $(10 \mathrm{~mL})$. The aqueous phase was separated and extracted with DCM (3 x $20 \mathrm{~mL}$ ). The combined organic layers were combined, dried $\left(\mathrm{MgSO}_{4}\right)$ and concentrated under reduced pressure. The residue was purified by flash column chromatography (silica, 50\% EtOAc in hexane) to yield the desired epoxide 9, (0.80 g, 74\%). GC/MS: (M+ O) 139 (6\%), 107 (13), 105 (8), 92 (26), 91 (100), 87 (12), 69 (11). ${ }^{1} \mathrm{H}$ NMR: $\left(\mathrm{CDCl}_{3}, 200 \mathrm{MHz}\right) \mathrm{d} 1.42$ - 1.93 (m, 2H), 2.51 (m, 1H), 2.67 (br s, 1H, $\mathrm{OH}), 2.78(\mathrm{~m}, 1 \mathrm{H}), 3.11(\mathrm{~m}, 1 \mathrm{H}) 3.35$ - $3.52(\mathrm{~m}, 2 \mathrm{H}), 4.05(\mathrm{~m}, 1 \mathrm{H}), 4.56(\mathrm{~s}, 2 \mathrm{H}), 7.25-7.35$ (m, 5H). $\left.{ }^{13} \mathrm{C} \mathrm{NMR:}\left(\mathrm{CDCl}_{3}\right) 50 \mathrm{MHz}\right)$ Two diastereomers d 35.92, 36.07, 46.62, 47.08, 49.59, 49.68, 68.28, 73.35, 73.91, 74.23, 127.70 (4C), 127.78 (2C), 128.42 (4C), 137.79 (2C), 150.35, 150.40. HRMS: $\mathrm{C}_{12} \mathrm{H}_{16} \mathrm{O}_{3}$ requires 208.1099. Measured, 208.1103.

1-Benzyloxy-4,5-epoxy-2-triethylsiloxy-pentane (10). The alcohol 9 (1.1 g, $5.3 \mathrm{mmol})$ was dissolved in DCM $(50 \mathrm{~mL})$ under $\mathrm{N} 2$ and cooled to $-78^{\circ}$ C. 2,6-Lutidine $(0.84 \mathrm{~g}, 0.923 \mathrm{~mL}) 7.9$ mmol) was added via syringe and the resulting mixture stirred for 15 minutes at $-78^{\circ} \mathrm{C}$. Triethylsily triflate $(1.68 \mathrm{~g}, 143 \mathrm{~mL}, 6.35 \mathrm{mmol})$ was then added via syringe and the reaction monitored by tlc (silica, 10\% EtOAc in hexane) and quenched at $-60^{\circ} \mathrm{C}$ with water $(30 \mathrm{~mL}$ ) when no starting material remained. The reaction was diluted with DCM (20 mL). The aqueous layer was separated and extracted with DCM (2 x $50 \mathrm{~mL})$, dried $\left(\mathrm{MgSO}_{4}\right)$ and concentrated under reduced pressure. The residue was purified via flash column chromatography (silica, 7\% 
EtOAc in hexane) to yield protected epoxy diol, 10, (0.5 g, 34\%). GC/MS: m/z $293\left(\mathrm{M}^{+}-29\right.$, 0.2\%), 221 (2), 210 (3), 187 (3), 185 (3), 173 (3), 146 (4), 145 (31), 117 (20), 115 (12), 92 (10), 91 (100). ${ }^{1} \mathrm{H}$ NMR: $\left(\mathrm{CDCl}_{3}, 200 \mathrm{MHz}\right)$ Two diastereomers (1:1) d $0.51(1, J=7.7 \mathrm{~Hz}, 3 \mathrm{x} 2 \mathrm{H}$, $\left.\mathrm{SiCH}_{2} \mathrm{CH}_{3}\right) 0.55$ (q, $J=7.7 \mathrm{~Hz}, 3$ x 2H, $\left.\mathrm{SiCH}_{2} \mathrm{CH}_{3}\right) 0.88$ (t, $J=7.7 \mathrm{~Hz}, 3$ x 3H, $\left.\mathrm{SiCH}_{2} \mathrm{CH}_{3}\right), 1.59$ -1.65 (m, 2 x 1H), 1.68 (t, $J=5.7 \mathrm{~Hz}, 2$ x 1H), 2.37 (dd, $J=5.2$, $2.7 \mathrm{~Hz}, 1 \mathrm{H}), 2.40$ (dd, $J=5.2$, $2.7 \mathrm{~Hz}, 1 \mathrm{H}$ ), 2.64 (dd, $J=5,4 \mathrm{~Hz}, 1 \mathrm{H}), 2.68$ (dd, $J=5,4 \mathrm{~Hz}, 1 \mathrm{H}), 2.96-2.98$ (m, 2 x 1H), 3.32 - 3.45 (m, 2 x 2H), 3.93 - 4.01 (m, 2 x 1H) 4.44 (s, 2H $\left.\mathrm{PhCH}_{2}\right) 7.16-7.25$ (m, 2 x 5H aromatic). ${ }^{13} \mathrm{C}$ NMR: $\left(\mathrm{CDCl}_{3}, 100 \mathrm{MHz}\right)$ Two diastereomers d 4.86 (3C), 4.89 (3C), 6.74 (3C, 6.75 (3C), 37.97, 38.05, 46.70, 47.55, 49.26, 49.46, 69.24, 69.50, 73.27, 73.35, 74.28, 74.63, 127.49, 127.50, 127.58 (2C), 127.59 (2C), 128.25 (2 x 2C), 138.20, 138.27.

4-(p-Methoxybenzyloxy)-but-1-ene. But-3-enol was converted to the p- methoxybenzyl ether in the normal way with $\mathrm{KH}$ and then 4-methoxy-benzylchloride, in $89 \%$ yield. The crude product (12 g, 89\%) was used without further purification. GC/MS: m/z $192\left(\mathrm{M}^{+}, 3.7 \%\right), 161$ (5.2), 136 (5.8), 121 (100), 91 (6.8), 89 (3.8), 78 (14.6), 77 (14.8), 55 (6.4). ${ }^{1} \mathrm{H}$ NMR: $\left(\mathrm{CDCl}_{3}\right.$, $200 \mathrm{MHz}$ ) d 2.70 (qt, $J=6.7,1.4 \mathrm{~Hz}, 2 \mathrm{H}), 3.84$ (t, $J=6.7 \mathrm{~Hz}, 2 \mathrm{H}), 4.13$ (s, 3H, OMe), 4.79 (s, 2H, H5), $5.34-5.49$ (m, 2H), $6.07-6.20$ (m, 1H), 7.22 (d, $J=8.7 \mathrm{~Hz}, 2 \mathrm{H}), 6.83$ (d, $J=8.7 \mathrm{~Hz}$, 2H). ${ }^{13} \mathrm{C} \mathrm{NMR:}\left(\mathrm{CDCl}_{3}, 50 \mathrm{MHz}\right) 34.16,55.15,69.21,72.46,113.67$ (2C), 116.23, 129.16 (2C), 130.46, 135.24, 159.06. HRMS: $\mathrm{C}_{11} \mathrm{H}_{17} \mathrm{O}_{2}\left(\mathrm{M}-\mathrm{CH}_{3}\right)$ requires 177.0914. Measured, 177.0917.

3-(4-Methoxybenzyl)oxypropanal (13). The above alkene (5.4 g, $28 \mathrm{mmol}$ ) was treated with $\mathrm{O}_{3}$ in the normal manner, but importantly, the reaction was monitored by TLC (silica; 30\% EtOAc in hexane; product, $\mathrm{R}_{\mathrm{f}}$ 0.27) and quenched immediately when no starting material remained. The product was purified by flash column chromatography (silica, 25\% EtOAc in hexane) to give 3-(4-methoxybenzyl)oxypropanal (1.3 g, 24\%). (This low yield could be improved by more rapid work-up). GC/MS: m/z 194 (M+10.1\%) 137 (63.6), 135 (6.5), 122 (9.7), 121 (100), 109 (15.0), 94 (8.4), 91 (10.9), 78 (19.5), 77 (27). ${ }^{1} \mathrm{H}$ NMR: (CDCl $\left.; 200 \mathrm{MHz}\right)$ d 2.65 (td, $J=6.1,1.9 \mathrm{~Hz}, 2 \mathrm{H}$ ), 3.76 (t, $J=6.1 \mathrm{~Hz}, \mathrm{CH}_{2} \mathrm{CH}_{2}$ overlapping with d 3.77), 3.77 (s, 3H, OMe), 4.44 (s, 2H, $\mathrm{PhCH}_{2}$ ), 6.85 (d, $\left.J=8.7 \mathrm{~Hz}, 2 \mathrm{H}\right), 7.22$ (d, $\left.J=8.7 \mathrm{~Hz}, 2 \mathrm{H}\right), 9.27$ (t, $J=$ $1.9 \mathrm{~Hz}, \mathrm{CHO}) .{ }^{13} \mathrm{C} \mathrm{NMR}:\left(\mathrm{CDCl}_{3} 50 \mathrm{MHz}\right) \mathrm{d} 43.82$ (2C), 55.22 (OMe), 63.47, 72.86, 113.78 (2C), 129.30 (2C), 129.87, 159.25, 201.20.

Bis-(4-isocarenyl)-allylborane (14). Bis-(4-isocarenyl)-allylborane was prepared as described for bis-(4-isocarenyl)-borane hydride. The product was not isolated but used immediately.

4-Methoxybenzyl protected enediol (15). 3-(4-Methoxybenzyloxy)propanal 13 was treated with borane 14 in identical fashion as for 2-benzyloxyethanol 6, to provide homallyl alcohol 15 in 40\% yield, after column chromatography (silica, 20\% EtOAc in hexane). GC/MS: m/z 236 (M+1\%), 189 (1), 163 (1), 137 (33), 136 (10), 122 (10), 121 (100), 91 (6). ${ }^{1} \mathrm{H}$ NMR: (CDCl $200 \mathrm{MHz}$ ) d 1.91 (m, 2H), 2.40 (dd, 2H), 3.31 (t, $J=5.7 \mathrm{~Hz}, 2 \mathrm{H}), 3.72$ (s, 3H, OMe), 4.34 (s, 2H), $4.89-4.92$ (m, 1H), $5.04-5.12$, (m, 2H), 5.23 (m, 1H), 6.91, (d, $J=8.7 \mathrm{~Hz}, 2 \mathrm{H}), 7.32$ (d, $J$ $=8.7 \mathrm{~Hz}, 2 \mathrm{H}) .{ }^{13} \mathrm{C} \mathrm{NMR}:\left(\mathrm{CDCl}_{3}\right) \mathrm{d} 38.73,41.81,55.13,68.47,70.24,113.71,117.36,129.20$, 129.91, 134.81, 159.14. HRMS: $\mathrm{C}_{14} \mathrm{H}_{20} \mathrm{O}_{3} \mathrm{Na}$ requires 259.1329. Measured, 259.1307.

4-Methoxybenzylidene acetals (18). Alcohol 15 (1.5 g, $6.36 \mathrm{mmol})$ was added to a suspension 
of dry, powdered $3 \Delta$ sieves $(8 \mathrm{~g})$ in DCM (20 mL) under $\mathrm{N}_{2}$. After stirring for 30 minutes, DDQ (2.16 g) was added, and after stirring for a further 10 minutes, the reaction was complete as judged by TLC (silica, 30\% EtOAc in hexane). The reaction mixture was filtered through celite and washed with $100 \mathrm{~mL}$ DCM. The filtrate was washed with sodium bicarbonate (3 x $150 \mathrm{~mL}$ ), dried $\left(\mathrm{MgSO}_{4}\right)$ and concentrated under reduced pressure. The crude product was then purified by flash chromatography (15\% EtOAc in hexane) to give the 4-methoxybenzylidene acetals 18 (0.50 g, 33\%). GC/MS: m/z 234 (M+, 21\%) 233 (23), 203 (3), 193 (33), 137 (34), 136 (41), 135 (100), 121 (20), 109 (21), 108 (22), 107 (10) 94 (11), 92 (10). ${ }^{1} \mathrm{H}$ NMR: (CDCl, $\left.200 \mathrm{MHz}\right)$ (major + minor isomers). d $1.47-1.56(\mathrm{~m}, 1 \mathrm{H}), 1.69-1.84(\mathrm{~m}, 1 \mathrm{H}), 2.24-2.50(\mathrm{~m}, 2 \mathrm{H}), 3.78$ (s, 3H, OMe), $3.81-3.93\left(\mathrm{~m}, 2 \mathrm{H}, \mathrm{OCH}_{2}\right) 4.09-4.29(\mathrm{~m}, 1 \mathrm{H}, \mathrm{OCH}), 5.04-5.18(\mathrm{~m}, 2 \mathrm{H}$, $\left.\mathrm{CH}=\mathrm{CH}_{2}\right), 5.77-5.98\left(\mathrm{~m}, 1 \mathrm{H}, \mathrm{CH}=\mathrm{CH}_{2}\right), 5.87(\mathrm{dm}, J=8.8 \mathrm{~Hz}), 7.42(\mathrm{dm}, J=8.8 \mathrm{~Hz}, 2 \mathrm{H}) .{ }^{13} \mathrm{C}$ NMR: d 30.68, 40.38, (C3 \& C5), 55.19, (OMe), 66.89, 76.51, 101.00, 113.49, 117.26, 127.26, 131.28, $133.86,159.77$.

Asymmetric dihydroxylation of 18 to protected tetrol, (19). This was conducted in the usual way using $t$-butanol/water $(1: 1)$ under $\mathrm{N}_{2}$, with $\mathrm{AD}-\mathrm{mix}-\forall$. The reaction mixture was stirred at $0^{\circ} \mathrm{C}$ and monitored by TLC (silica, 30\% EtOAc in hexane). After 3 days the reaction was quenched by the addition of $20 \% \mathrm{Na}_{2} \mathrm{~S}_{2} \mathrm{O}_{3}$ aqueous solution and the reaction stirred for a further hour. After concentration to remove $t$-butanol, brine was added and the mixture extracted with ether $(5 \times 5 \mathrm{~mL})$. The combined ether layers were dried $\left(\mathrm{MgSO}_{4}\right)$ concentrated and flash chromatographed (silica; 5\% MeOH in DCM) to give diol (19) (0.75 g, 44\% yield). ${ }^{1} \mathrm{H}$ NMR: $\left(\mathrm{CDCl}_{3}, 400 \mathrm{MHz}\right)$ (Isomer Mixture). d $1.44-1.55$ (m, 2 x 1H), 1.68 - 1.72 (m, 2 x 2H), 1.8 $1.94(\mathrm{~m}, 2 \times 1 \mathrm{H}), 3.44-3.50$ (m, 2 x 1H), $3.56-3.66$ (m, 2 x 1H), $3.93-4.30$ (m, 2 x 2H), 4.11 $(\mathrm{m}, 2 \times 1 \mathrm{H}), 4.21(\mathrm{~m}, 2 \times 1 \mathrm{H}), 5.45$ (s, 1H, major diastereomer), $5.48(\mathrm{~m}, 1 \mathrm{H}$, minor diastereomer), 6.85 (dm, $J=8.8 \mathrm{~Hz}, 2 \times 2 \mathrm{H}$ ), 7.35 (dm, $J=8.8 \mathrm{~Hz}, 2 \mathrm{H}$ minor isomer), 7.36 (dm, $J=8.8 \mathrm{~Hz}$ ) major diastereomer. ${ }^{13} \mathrm{C}$ NMR: Major diastereomer: d 31.21, 38.84, 55.27, 66.89, 66.94, 68.68, 74.31, 101.17, 133.64 (2C), 127.24 (2C), 131.05, 159.96. Minor diastereomer: d 31.41, 38.98, 55.27, 66.50, 66.93, 71.00, 76.81, 101.20, 113.72 (2C), 127.25 (2C), 130.73, 160.07. HRMS: $\mathrm{C}_{14} \mathrm{H}_{20} \mathrm{O}_{5}$ requires 268.13107. Measured, 268.1312.

Monotosylation of diol (19). This was conducted in the usual way with pyridine as solvent, tosyl chloride $(0.34 \mathrm{~g}, 1.8 \mathrm{mmol})$ was added in one portion. The reaction was monitored and by TLC (silica; 50\% EtOAc in hexane). After stirring at room temperature for 5 hours the reaction was stored overnight at $0^{\circ} \mathrm{C}$. More tosyl chloride $(100 \mathrm{mg}$ ) was added and the reaction was stirred for a further $6 \mathrm{~h}$ at room temperature. The reaction mixture was then diluted with ether $(20 \mathrm{~mL})$, washed with saturated aqueous $\mathrm{CuSO}_{4}(3 \times 20 \mathrm{~mL})$, then with saturated aqueous $\mathrm{NaHCO} 3$ (2 x $20 \mathrm{~mL}$ ), dried $\left(\mathrm{MgSO}_{4}\right)$ and concentrated under reduced pressure. The residue was purified by flash column chromatography (silica; 40\% EtOAc in hexane) to provide the mono tosylate, (0.5 g, 66\%). ${ }^{1} \mathrm{H} \mathrm{NMR}$ : $\left(\mathrm{CDCl}_{3}, 400 \mathrm{MHz}\right.$ ) (Two diastereomers). d 1.42 - 1.51 (m, $2 \mathrm{x}$ 1H, $\mathrm{CH}_{2}$ ), 1.69 (dd, $\left.J=6.44,5.56 \mathrm{~Hz}, 2 \times 1 \mathrm{H}\right), 1.75-1.87$ (m, 2 x 2H), 2.42 (s, 2 x 3H, PhMe), 3.78 (s, 2 x 3H, OMe), 3.89 - 4.19 (m, 2 x 5H), 4.21 (ddd, $J=11.44,4.92,1.04$ Hz, 2 x 1H), 5.42 (s, 1H, major diastereomer), 5.44 (s, 1H, minor diastereomer), 6.84 (dm, $J=8.8 \mathrm{~Hz}, 2 \mathrm{H}$, 
minor diastereomer), $6.85(\mathrm{dm}, J=8.5 \mathrm{~Hz}, 2 \mathrm{H}$, major diastereomer), $7.29-7.35$ (m, $2 \times 4 \mathrm{H}$, tosylate aromatics), $7.75\left(\mathrm{dm}, J=8.8 \mathrm{~Hz}, 2 \times 2 \mathrm{H}\right.$, aromatic). ${ }^{13} \mathrm{C} \mathrm{NMR}$ : $\left(\mathrm{CDCl}_{3}, 100 \mathrm{MHz}\right)$ Major diastereomers: d 21.60 (MePh), 31.19, 38.48, 55.29 (MeOPh), 66.17, 66.85, 73.65, 73.71, 101.12, 113.63 (2C), 127.24, 127.96 (2C), 129.88, 129.91, 130.96, 132.70, 145.03, 159.98. Minor diastereomer: d 20.99, 31.23, 38.74, 55.29 (superimposed on major isomer), 60.37, 68.42, 73.11, 76.15, 101.12 (superimposed on major isomer), 113.68 (2C), 127.13 (2C), 127.85 (2C), 129.91 (superimposed on major isomer), 130.70, 132.75, 144.95, 159.98 (superimposed on major isomer).

Protected epoxy diol (20). To the above tosylate $(0.5 \mathrm{~g}, 1.2 \mathrm{mmol})$ in dry methanol $(15 \mathrm{~mL})$, anhydrous $\mathrm{K}_{2} \mathrm{CO}_{3}(0.33 \mathrm{~g}, 2.37 \mathrm{mmol})$ was added. The reaction mixture was stirred at room temperature and was complete after $1 \mathrm{~h}$, as judged by TLC (silica; 40\% EtOAc in hexane). The reaction was concentrated to remove the methanol, then diluted with water and extracted with ether (3 x $30 \mathrm{~mL}$ ), dried (MgSO4) and concentrated to provide the desired epoxide (20) (0.24 g, 80\%). GC/MS: m/z 250 (M+18\%), 219 (2), 193 (11), 176 (2), 152 (11), 135 (100), 108 (14), 94 (9), 77 (24), 41 (20). The crude product was purified by flash column chromatography. ${ }^{1} \mathrm{H}$ NMR: (2 diastereomers about benzylidene $\mathrm{CH}$ ) 7.42, 7.45 (d ar, 2 x 2H, CH), 6.82, 6.88 (d ar, 2 x 2H, $\mathrm{CH}$ ), 5.42, 5.46 (s, $2 \times 1 \mathrm{H}, \mathrm{CHPMP}$ ), 3.84, 4.25 (m, 2 x 3H, $\mathrm{CH}$ and $\mathrm{CH}_{2}$ in acetal ring), 3.80 (m, $2 \times 2 \mathrm{H}, \mathrm{CH}_{2} \mathrm{O}$ ), 3.78 (s, 2 x 3H, MeO), $2.86-2.94$ (m, 2 x 4H, CH2S), $1.60-2.10$ (m, $2 \times 8 \mathrm{H}$ ). ${ }^{13} \mathrm{C}$ NMR: (CDCl 3 , 2 isomers) 164.48, 163.29 (MeOC), 131.55, 131.24 (ar 2CH), 129.89, 130.01 (ar quarternary C), 113.63, 114.18 (ar, 2CH), 101.00, 100.89 (benzylidene $\mathrm{CH}$ ), 76.15, 76.12 $\left(\mathrm{CH}_{2} \mathrm{CHOCH}\right), 74.67(\mathrm{COH}), 73.76,72.67\left(\mathrm{CH}_{2} \mathrm{O}\right), 55.15,55.45$ (OMC), $49.97\left(\mathrm{CH}_{2} \mathrm{~S}\right), 33.16$, $32.79\left(2 \mathrm{CH}_{2} \mathrm{~S}\right), 29.76,28.52,28.39,27.78,27.71,27.03\left(\mathrm{CH}_{2}\right.$ signals $)$. HRMS: $\mathrm{C}_{14} \mathrm{H}_{18} \mathrm{O}_{4}$ requires 250.1204. Measured, 250.1208.

Epoxide (17). Enediol 15 was treated with $\mathrm{m}-\mathrm{CPBA}$ in DCM in the normal way to provide protected epoxydiol 16 which was treated with DDQ in DCM (4 $\Delta$ sieves) to provide the protected epoxydiol 17, which was purified as described for 20. ${ }^{1} \mathrm{H}$ NMR: $\left(\mathrm{CDCl}_{3}, 200 \mathrm{MHz}\right)(4$ diastereomers, resolved into pairs about the benzylidene $\mathrm{CH}$ centre at this field strength). d 1.48 - 160 (m, 2H), $1.73-2.07$ (m, 2H), $2.49-2.56$ (m, 2 x 1H), $2.75-2.83$ (m, 2 x 1H), $3.10-3.19$ (m, $2 \times 1 \mathrm{H}$ ), 3.78 (s, $2 \times 3 \mathrm{H}, \mathrm{OMe}$ ), $3.83-4.30$ (M, 1H), 5.47 (s, 1H, minor isomer), 5.51 (s, $1 \mathrm{H}$, major isomer), $6.87(\mathrm{dm}, J=8.8 \mathrm{~Hz}, 2 \mathrm{x} 2 \mathrm{H}), 7.40$ (br d, $J=8.4 \mathrm{~Hz}, 2 \times 2 \mathrm{H}) .{ }^{13} \mathrm{C}$ NMR: $\left(\mathrm{CDCl}_{3}\right.$, $50 \mathrm{MHz}$ ) Major isomer d 31.46, 38.36, 47.27, 49.16, 55.19 (superimposed on minor isomer, OMe), 66.69, 74.75, 100.93, 113.48 (2C), 127.19 (2C), 131.34, 159.77. Minor isomer d 31.46, 39.36. 46.27, 48.86, 55.19 (superimposed on minor isomer, OMe) 66.79, 74.75, 100.93, 113.48 (2C), 127.19 (2C), 131.34, 159.77. Minor isomer d 30.76, 39.37, 46.72, 48.86, 55.19 (superimposed on major isomer, OMe) 66.82, 74.34, 101.04, 113.52 (2C), 127.24 (2C), 131.06, 159.82.

Monoalkylation of 1,3-dithiane (21). ${ }^{n}$ Butyl lithium (2.62 mL of a $2.2 \mathrm{M}$ solution in hexane, $5.76 \mathrm{mmol}$ ) was added via syringe to 1,3-dithiane ( $0.48 \mathrm{~g}, 1.92 \mathrm{mmol})$ dissolved in dry THF (20 $\mathrm{mL}$ ) under $\mathrm{N}_{2}$ and cooled to $-35^{\circ} \mathrm{C}$. The reaction mixture was stirred at $-35^{\circ} \mathrm{C}$ for 2 hours, after which the epoxide 17 in THF ( $5 \mathrm{~mL}$ ) was added via cannula. The reaction with stirred for a 
further 1 hour at $-35^{\circ} \mathrm{C}$ and monitored via TLC (silica; 50\% EtOAc in hexane). The sluggish reaction was allowed to warm to room temperature and quenched by the addition of EtOAc (20 $\mathrm{mL}$ ) and then saturated aqueous $\mathrm{NaHCO}_{3}(30 \mathrm{~mL})$. The mixture was concentrated to remove THF, then extracted with EtOAc ( $3 \times 40 \mathrm{~mL})$, dried $\left(\mathrm{MgSO}_{4}\right)$ and concentrated. The crude product was purified by flash column chromatography (silica; 40\% EtOAc in hexane) to provide dithiane 21 in 73\% yield. GC/MS: m/z 278 (9\%), 260 (23), 161 (22), 159 (25), 145 (36), 133 (30), 132 (28), 127 (30), 119 (77), 106 (23), 101 (35), 75 (24), 74 (25), 73 (28), 59 (42), 55 (32). ${ }^{1} \mathrm{H}$ NMR: $\left(\mathrm{CDCl}_{3}, 400 \mathrm{MHz}\right.$, four diastereomers, two resolved) d $1.15-2.10$ (m, 10H), 2.7 2.95 (m, 4H), 3.76 (s, OMe, minor isomer), 3.77 (s, 3H), $3.9-4.0$ (td, 1H), $4.07-4.28$ (m, 4H), 5.44 (s, 1H, major isomer), 5.46 (s, OCHO minor isomer), 6.82 - 6.87 (m, 2H), 7.33 - 7.37 (m, 2H). ${ }^{13} \mathrm{C}$ NMR: (CDCl3, $100 \mathrm{MHz}$ ) Major isomer: d 25.87, 30.03, 30.32, 31.01, 42.51, 42.93, 44.13, 55.25, 65.22, 66.93, 74.46, 101.15, 113.59 (2C), 127.25 (2C) 131.05, 159.90. Minor Isomer: d 25.97, 30.09, 30.48, 31.38, 42.72, 42.93, 43.80, 55.25, 66.88, 67.53, 77.5, 101.15, 113.63 (2C), 127.17 (2C) 130.70, 160.01. This alcohol 21 was carried on to the ether 22.

Methylation of dithiane 21 to ether 22. The alcohol 21 (0.48 g, $1.3 \mathrm{mmol})$ dissolved in THF $(10 \mathrm{~mL})$ was added via cannula (5 mL wash) into a stirred suspension of $\mathrm{KH}(0.22 \mathrm{~g}$ of a $35 \%$ suspension in oil; washed with hexane and THF) at $0^{\circ} \mathrm{C}$ under $\mathrm{N}_{2}$. After 5 minutes the reaction mixture was warmed to room temperature and stirred for 15 minutes. After recooling to $0^{\circ} \mathrm{C}$, MeI (1.85 g, $0.81 \mathrm{~mL}, 13 \mathrm{mmol}$ ) was added neat, via syringe. After stirring for 10 minutes at $0^{\circ}$ $\mathrm{C}$ the reaction mixture was stirred at room temperature for 20 minutes, then quenched by the careful addition of cold water. The mixture was concentrated to remove THF, then extracted with EtOAc ( 3 x $40 \mathrm{ml}$ ), dried $\left(\mathrm{MgSO}_{4}\right)$ and concentrated. The residue was purified by flash column chromatography (silica, 25\% EtOAc in hexane) to provide the methyl ether $22(0.27 \mathrm{~g}, 60 \%)$. GC/MS: m/z 384 (M+30\%), 383 (18), 263 (23), 231 (67), 216 (30), 193 (19), 175 (52), 159 (33), 145 (38), 141 (34), 137 (90), 136 (91), (lower m/z). ${ }^{1} \mathrm{H}$ NMR: (CDCl $3,400 \mathrm{MHz}$ ) (Mixture of four diastereomers, 2 diastereomers resolved). d $1.44-1.53$ (m, 2 x 1H), $1.64-2.09$ (m, 2 x 7H), 2.74 - 2.91 (m, 2 x 4H, SCH ), 3.33 (s, 3H, OMe), 3.39 (s, 3H, OMe), 3.68 - 3.79 (M, 2 x 1H), 3.77 (s, 2 x 3H, OMe), $3.90-4.02$ (m, 2 x 2H), $4.12-4.25$ (2 x 2H), 5.45 (s, 1H, OCHO), 5.46 (s, 1H, OCHO), 6.85 (dm, $J=8.8 \mathrm{~Hz}, 2 \mathrm{H}), 6.86$, (dm, $J=8.8 \mathrm{~Hz}, 2 \mathrm{H}) 7.40$ (dm, $J=8.8 \mathrm{~Hz}$, 2 x 2H). ${ }^{13} \mathrm{C} \mathrm{NMR:}\left(\mathrm{CDCl}_{3}, 100 \mathrm{MHz}\right) 25.90,26.00\left(\mathrm{CH}_{2}\right), 30.10\left(2 \mathrm{C}, \mathrm{CH}_{2}\right), 30.34,30.36\left(\mathrm{CH}_{2}\right)$, 31.58, 31.73 (CH2), 39.25, 39.83 (SCH2), 40.81, $41.50\left(\mathrm{SCH}_{2}\right), 43.34,43.69$ (SCHS) 55.26, 55.27 (OMe), 56.54, $57.75(\mathrm{OMe}), 66.93,66.96\left(\mathrm{OCH}_{2}\right), 73.73,73.92,74.07,74.11(\mathrm{OCH})$, 100.82, 100.83 (OCHO), 113.50 (2C), 113.55 (2C), 127.22 (4C), 131.30, 131.38, 159.78, 159.82. HRMS: $\mathrm{C}_{19} \mathrm{H}_{28} \mathrm{O}_{4} \mathrm{~S}_{2}$. Na requires 407.1326. Measured, 407.1342.

Alkylation of dithiane 22 to 23. To dithiane 22 (0.17 g, $0.44 \mathrm{mmol})$ dissolved in dry THF (2.5 $\mathrm{mL}$; distilled off $\mathrm{Na}$ and then $\mathrm{LiAlH}_{4}$ ) and cooled to $-30^{\circ} \mathrm{C}$ (dry ice/ $\mathrm{CCl}_{4}$ ) under $\mathrm{N} 2$, was added ${ }^{t} \mathrm{BuLi}$ (288 $\mu \mathrm{L}, 0.48 \mathrm{mmol}$ ). After stirring for 10 minutes, HMPA (156 $\mu \mathrm{L}, 0.88 \mathrm{mmol}$ ) was added via syringe and the mixture stirred at $-30^{\circ} \mathrm{C}$ for a further 1 hour. Epoxide $10(0.17 \mathrm{~g}, 170$ $\mu \mathrm{L}, 0.53 \mathrm{mmol}$ ) was added neat via syringe, the mixture stirred for a further 10 minutes at $-30^{\circ}$ $\mathrm{C}$ then warmed to $0^{\circ} \mathrm{C}$ and stirred for a further 1 hour. The reaction was quenched with water, 
extracted with ether ( 3 x $20 \mathrm{~mL})$, dried $\left(\mathrm{MgSO}_{4}\right)$ and concentrated. The residue was purified via flash chromatography (silica; 25\% EtOAc in hexane) to provide the bis-alkylated dithiane 23, $135 \mathrm{mg}$, (43\%). ${ }^{1} \mathrm{H}$ NMR: $\left.\left(\mathrm{CDCl}_{3}\right) 400 \mathrm{MHz}\right) \mathrm{d} 0.56-0.65$ (m, 2 x 2H, $\left.\mathrm{SiCH}_{2} \mathrm{CH}_{3}\right), 0.91-0.97$ (m, 3 x 3H, $\left.\mathrm{SiCH}_{2} \mathrm{CH}_{3}\right), 1.50-2.29(\mathrm{~m}, 12 \mathrm{H}), 2.59-2.86(\mathrm{~m}, 4 \mathrm{H}), 3.25-3.49$ (m, 5H), $3.75-$ 4.55 (m, 11H), 5.43 - 5.47 (m, 1H), 6.83 - 6.88 (m, 2H), 7.21 - 7.33 (m, 5H), 7.39 - 7.41 (m, 2H). HRMS: $\mathrm{C}_{37} \mathrm{H}_{58} \mathrm{O}_{7} \mathrm{~S}_{2} \mathrm{Si}$ requires 706.3393. Measured, 706.3395. Further characterisation of this diastereomeric mixture prior to spiroacetalisation was not attempted.

Spiroacetalisation of 23 to 24. Dithiane 23 (70 mg in MeOH/water (9:1, $5 \mathrm{~mL}$ ) was treated with bis-trifluoroacetoxy iodobenzene (Stork's reagent: $140 \mathrm{mg}$ ) and the mixture was stirred and allowed to warm to room temperature. The reaction was monitored by TLC (silica; $5 \% \mathrm{MeOH}$ in DCM) and quenched after 15 minutes by the addition of saturated aqueous $\mathrm{NaHCO}_{3}(5 \mathrm{~mL})$. The mixture was concentrated to remove $\mathrm{MeOH}$ and then extracted with ether $(3 \mathrm{x} 10 \mathrm{~mL})$ and EtOAc ( 1 x $20 \mathrm{~mL})$. The combined organic layers were dried $\left(\mathrm{MgSO}_{4}\right)$ and concentrated under reduced pressure. Initial purification of the residue by flash column chromatography (silica, 5\% $\mathrm{MeOH}$ in DCM) was followed by gradient elution on semi-preparative reverse phase HPLC (75\% acetonitrile/water through to 95\% acetonitrile/water) to provide the diastereomers A - G whose spectra are tabulated and discussed in the text. Representative HPLC times for some of the spiroacetal isomers under these conditions were $16.6 \mathrm{mins}$ for isomer $\mathrm{C}$ and 11.6 mins for isomer F. Isomers B and $\mathrm{E}$ were obtained as a mixture which eluted at13.1mins. The peak area ratios of (B and $\mathrm{E}$ ): $\mathrm{C}: \mathrm{F}$ was 2.4:1.2:1. Isomers $\mathrm{B}$ and $\mathrm{E}$ were separated by further reverse phase HPLC elutions to afford pure $B$ and $E$ in a ratio of 1.6:1. Isomers A, D and G were separated under similar chromatographic conditions and were obtained in relatively similar quantities to B,E,C and $\mathrm{F}$ with the exception of isomer A of which only a small amount was obtained. HRMS: $\mathrm{C}_{20} \mathrm{H}_{30} \mathrm{O}_{6}$ requires 366.2042. Measured, 366.2038.

\section{Acknowledgements}

The authors are grateful to the Australian Research Council for a postdoctoral fellowship (to MFJ) and to Dr I. Paterson and Dr. Debra Wallace (University of Cambridge, UK) for a copy of the ${ }^{1} \mathrm{H}$ NMR spectrum of their synthesized CD-spiroacetal.

\section{References and Notes}

1. Pettit, G.R.; Cichacz, Z.A.; Gao, R.; Herald, C.L.; Boyd, M.R.; Schmidt, J.M.; Hooper, J.N.A. J.Org. Chem. 1993, 58, 1302.

2. Pettit, G.R.; Cichacz, Z.A.; Herald, C.L.; Gao, F.; Boyd, M.R.; Schmidt, J.M.; Hamol, E.; Bai, R. J. Chem. Soc. Chem. Commun. 1994, 1605.

3. (a) Kobayashi, M.; Aoki, S.; Kitagawa, I. Tetrahedron Lett. 1994, 35, 1243. (b) Kobayashi, 
M.; Aoki, S.; Sakai, S.; Kihara, N.; Sasaki, T.; Kitagawa, I. Chem. Pharm. Bull. 1993, 41, 989.

4. Fusetani, N.; Shinoda, K.; Matsunoga, S. J. Am. Chem. Soc. 1993, 115, 3977.

5. Aoki, S.; Nemoto, N.; Kobayashi, Y.; Kobayashi, M.; Kitagawa, I. Tetrahedron, 2001, 57, 2289.

6. For a background summary, see Pietruszka, J. Angew. Chem. Int. Ed. 1998, 37, 2629.

7. Pettit, G.R. J. Nat. Prod. 1996, 59, 812.

8. For a comprehensive listing of these contributions see Crimmins, M.T.; Katz, J.D.; McAtee, L.C.; Tabet, E.A.; Kirincich, S.J. Org. Lett. 2001, 3, 949 and also ref. 6.

9. Evans, D.A.; Trotter, W.; Coleman, P.J.; Cote, B.; Dias, L.C. ; Rajapakse, H.A.; Tyler, N.A. Tetrahedron 1999, 55, 8671 and references therein.

10. (a) Guo, J.; Duffy, K.J.; Stevens, K.L.; Dalko, P.I.; Roth, R.M.; Hayward, M.M.; Kishi, Y. Agnew. Chem. Int. Ed. 1998, 37, 187. (b) Hayward, M.M.; Roth, R.M.; Duffy, K.J.; Dalko, P.I.; Stevens, K.L.; Guo, J.; Kishi, Y. Agnew. Chem. Int. Ed. 1998, 37, 192.

11. Smith, A.B., III; Lai, Q.; Doughty, V.A.; Zhuang, L.; McBriar, M.D.; Kerns, J.K.; Brook, C.S.; Murase, N.; Nakayama, K. Angew. Chem. Int. Ed. 2001, 40, 196.

12. For illustrative previous approaches to this CD spiroacetal system (other than in ref. 9,10) see (a) Hayes, C.J. Heathcock, C.H. J. Org. Chem. 1997, 62, 2678. Claffey, M.M.; Hayes, C.J.; Heathcock, C.H. J. Org. Chem. 1999, 64, 8267. (b) Paterson, I.; Wallace, D.J.; Gibson, K.R. Tetrahedron Lett. 1997, 38, 8911. Paterson, I.; Wallace, D.J.; Okalla, R.M. Tetreahedron Lett. 1998, 39, 8545. (c) Paquette, L.A.; Braun, A. Tetrahedron Lett. 1977, 38, 5119. (d) Smith, A.B. III ; Zhuang, L.; Brook, C.S.; Liu, Q.; Moser, W.H.; Trout, R.E.L.; Boldi, A.M. Tetrahedron Lett. 1997, 38, 8671. (e) Zemribo, R.; Mead, K.T. Tetrahedron Lett. 1998, 39, 3895. Zembiro, R.; Mead, K.T. Tetrahedron Lett. 1998, 39, 3891.

13. Pothier, N.; Goldstein, S.; Deslongchamps, P. Helv. Chim. Acta. 1992, 75, 604. See also ref. 12(b), 12(d) for example.

14. Blackwood, J.E.; Gladys, C.L.; Loenig, K.L.; Petrarca, N.E.; Rush, J.E. J. Am. Chem. Soc. 1969, 90, 509.

15. Denmark, S.E.; Herbert, B. J. Org. Chem. 2000, 65, 2887.

16. Brown, H.C.; Randad, R.S.; Bhat, K.S.; Zainlewicz, M.; Racherla, V.S. J. Am. Chem. Soc. 1990, 112, 2839.

17. For fragmentation behaviour of spiroacetals see Francke, W.; Kitching, W. Current Organic Chemistry 2001, 5, 233.

18. Tu, Y.Q.; Hubener, A.; Zhang, H.; Moore, C.J.; Fletcher, M.T.; Hayes, P.; Dettner, K.; Francke, W.; McErlean, C.S.P.; Kitching, W. Synthesis 2000, No. 13, 1956.

19. (a) Mori, K.; Watanabe, H. Tetrahedron 1986, 42, 295. (b) Perkins, M.V.; Jacobs, M.F.; Kitching, W.; Cassidy, P.J.; Lewis, J.A.; Drew, R.A.I. J. Org. Chem. 1992, 57, 3365.

20. Dominey, A.P.; Goodman, J.M. Org. Lett. 1999, 1, 473 and references therein.

21. For NMR data for the CD-ring spiroacetal, but all with different combinations of substituent or protecting groups see, for example, ref 12(a), (b), (c), (e) and 9. 